OPEN ACCESS

Edited by:

Tracy Raivio,

University of Alberta, Canada

Reviewed by:

Vincent Tam

Temple University, United States Andrés González,

Aragon Institute for Health Research

(IIS Aragon), Spain

*Correspondence:

Sigrun Lange

S.Lange@westminster.ac.uk

Jameel M. Inal

j.inal@herts.ac.uk

Specialty section:

This article was submitted to Molecular Bacterial Pathogenesis,

a section of the journal

Frontiers in Cellular and Infection Microbiology

Received: 05 April 2019 Accepted: 11 June 2019

Published: 27 June 2019

Citation:

Kosgodage US, Matewele $P$ Mastroianni G, Kraev I, Brotherton D, Awamaria B, Nicholas AP, Lange S and Inal JM (2019) Peptidylarginine Deiminase Inhibitors Reduce Bacterial Membrane Vesicle Release and Sensitize Bacteria to Antibiotic Treatment.

Front. Cell. Infect. Microbiol. 9:227.

doi: 10.3389/fcimb.2019.00227

\section{Peptidylarginine Deiminase Inhibitors Reduce Bacterial Membrane Vesicle Release and Sensitize Bacteria to Antibiotic Treatment}

\author{
Uchini S. Kosgodage ${ }^{1}$, Paul Matewele ${ }^{1}$, Giulia Mastroianni ${ }^{2}$, Igor Kraev ${ }^{3}$, \\ Dominik Brotherton ${ }^{4}$, Brigitte Awamaria ${ }^{1}$, Anthony P. Nicholas ${ }^{5}$, Sigrun Lange ${ }^{6 *}$ and \\ Jameel M. Inal ${ }^{4 \star}$
}

${ }^{1}$ Cellular and Molecular Immunology Research Centre, School of Human Sciences, London Metropolitan University, London, United Kingdom, ${ }^{2}$ School of Biological and Chemical Sciences, Queen Mary University of London, London, United Kingdom, ${ }^{3}$ School of Life, Health and Chemical Sciences, The Open University, London, United Kingdom, ${ }^{4}$ Bioscience Research Group, Extracellular Vesicle Research Unit, School of Life and Medical Sciences, University of Hertfordshire, Hatfield, United Kingdom, ${ }^{5}$ Department of Neurology, University of Alabama at Birmingham, Birmingham, AL, United States, ${ }^{6}$ Tissue Architecture and Regeneration Research Group, School of Life Sciences, University of Westminster, London, United Kingdom

Outer membrane and membrane vesicles (OMV/MV) are released from bacteria and participate in cell communication, biofilm formation and host-pathogen interactions. Peptidylarginine deiminases (PADs) are phylogenetically conserved enzymes that catalyze post-translational deimination/citrullination of proteins, causing structural and functional changes in target proteins. PADs also play major roles in the regulation of eukaryotic extracellular vesicle release. Here we show phylogenetically conserved pathways of PAD-mediated OMV/MV release in bacteria and describe deiminated/citrullinated proteins in E. coli and their derived OMV/MVs. Furthermore, we show that PAD inhibitors can be used to effectively reduce OMV/MV release, both in Gram-negative and Gram-positive bacteria. Importantly, this resulted in enhanced antibiotic sensitivity of both $E$. coli and $S$. aureus to a range of antibiotics tested. Our findings reveal novel strategies for applying pharmacological OMV/MV-inhibition to reduce antibiotic resistance.

Keywords: outer-membrane vesicles (OMVs), peptidylarginine deiminase (PAD), deimination/citrullination, antibiotic sensitivity, E. coli VCS257, S. aureus subsp. aureus Rosenbach

\section{INTRODUCTION}

Outer membrane vesicles (OMVs), and membrane vesicles (MVs), are released from Gram-negative and Gram-positive bacteria and participate in bacterial communication, facilitating the transfer of cargo molecules (Dorward and Garon, 1990; Li et al., 1998; Fulsundar et al., 2014; Jan, 2017; Toyofuku et al., 2019). OMVs are released in greater abundance from Gram-negative than Gram-positive bacteria, are crucial for bacterial survival and form part of the stress response (McBroom and Kuehn, 2007; Macdonald and Kuehn, 2013; Jan, 2017). Research on bacterial OMVs has grown rapidly in recent years, including their use as bioengineered drug delivery vehicles (Gujrati et al., 2014; Bitto and Kaparakis-Liaskos, 2017) and in vaccine development (Gaillard et al., 2014; Choi et al., 2015; Alves et al., 2016; Raeven et al., 2016; Wang et al., 2017). 
Peptidylarginine deiminases (PADs) are a group of calciumactivated enzymes that are preserved throughout phylogeny from bacteria to mammals and catalyze the post-translational deimination/citrullination of arginine residues to citrulline, causing structural, and functional changes in target proteins (Vossenaar et al., 2003; Wang and Wang, 2013; Witalison et al., 2015; Magnadóttir et al., 2018). Five mammalian PAD isozymes have been identified which participate in physiological and pathophysiological processes, including autoimmune and neurodegenerative diseases, cancer and sepsis (Wang and Wang, 2013; Witalison et al., 2015; Kosgodage et al., 2017, 2018; Lange et al., 2017; Biron et al., 2018; Costa et al., 2018). Recent studies have highlighted novel PAD-mediated mechanisms of extracellular vesicle (EV) release in eukaryotic cells (Kholia et al., 2015; Kosgodage et al., 2017, 2018; Gavinho et al., 2019) but a link to conserved mechanisms in bacterial OMV/MV release has hitherto not been made. While several PAD isozymes, with different preferences for target proteins, are present higher in phylogeny, in bacteria only one PAD form has been described. For example in Porphyromonas gingivalis, a Gram-negative bacterium, the association of PAD and its citrullinome has been linked to neo-epitope generation in oral cavity disease and rheumatoid arthritis (Maresz et al., 2013; Gully et al., 2014; Stobernack et al., 2016; Bereta et al., 2019). However, although an arginine deiminase (AD) has been identified in the Eschericia coli genome (GenBank: EDV68547.1), also a Gram-negative bacterium, no significant data is available to confirm the presence of an associated citrullinome. Furthermore, an $\mathrm{AD}$ has also been identified in Staphylococcus aureus (GenBank: BBA25170.1), a Gram-positive bacterium.

Our previous studies established that EV release from cancer cells is largely PAD-driven, can be effectively inhibited using pharmacological PAD inhibitors and that such inhibition sensitizes cancer cells to chemotherapy (Kholia et al., 2015; Kosgodage et al., 2017, 2018). Therefore, we set out to investigate if this could be a phylogenetically conserved mechanism and in the same vein, be exploited to sensitize bacteria to antibiotics.

The role of OMVs in biofilm formation and in protecting biofilms via adsorption of antimicrobial agents has indeed been previously recognized (Schooling and Beveridge, 2006; Manning and Kuehn, 2011; Toyofuku et al., 2019). Thus, application of OMV inhibition could potentially lower resistance to antibiotics and be useful in minimizing multi-drug resistance associated with antibiotic treatment.

Using a range of antibiotics, we determined the effect of several PAD-specific inhibitors on changes in OMV/MV release and on antibiotic sensitivity of Gram-negative (E. coli VCS257) and Gram-positive bacteria (S. aureus subsp. aureus Rosenbach).

The PAD inhibitors tested were first generation pan-PAD inhibitor Cl-amidine (Luo et al., 2006), second generation pan-PAD inhibitor BB-Cl-amidine (Knight et al., 2014), PAD2 inhibitor AMF30a (Muth et al., 2017), and PAD4 inhibitor GSK199 (Lewis et al., 2015). The following range of antibiotics was tested in combination with the OMV/MV inhibitors: (i) Colistin (Polymyxin E), which acts on the lipoglycans and endotoxins of the Gram-negative bacterial cell membrane (Falagas et al., 2005; Livermore et al., 2011; Yahav et al., 2012;
Yu et al., 2019); (ii) Vancomycin, which alters the permeability of the cell membrane and selectively inhibits ribonucleic acid synthesis (Watanakunakorn, 1984). It is effective against Grampositive bacteria, including Staphylococcus, Streptococcus, and Listeria and prescribed for serious skin, blood-borne and joint infections as well as meningitis caused by methicillinresistant Staphylococcus aureus (MRSA) (Ng et al., 2014); (iii) Rifampicin, which inhibits DNA-dependent RNA polymerase activity, suppressing the initiation of RNA synthesis (Campbell et al., 2001). It is effective against a broad spectrum of bacteria, mainly Gram-positive cocci (van Ingen et al., 2011); (iv) Kanamycin, which binds to the bacterial $30 \mathrm{~S}$ ribosomal subunit, causing misreading of t-RNA and inhibition of bacterial protein synthesis (Hoerr et al., 2016). It is active against most Gram-negative bacteria and some Gram-positive bacteria (Salian et al., 2012); (v) Erythromycin, which inhibits bacterial protein synthesis by binding to bacterial 50S ribosomal subunits (Ianaro et al., 2000). It is effective against Gram-positive bacteria including Staphylococci, Streptococci and Pneumococci and Gram-negative sporing and non-sporing gut anaerobes, such as E. coli (Jelić and Antolović, 2016).

Here we show that OMV/MV release can be regulated via PAD-mediated pathways both in E. coli VCS257 and S. aureus subsp. aureus Rosenbach and that this can be exploited to enhance antibiotic effectivity of selected antibiotics in both Gram-negative and Gram-positive bacteria. Furthermore, in E. coli we identified deiminated/citrullinated proteins both in the bacterial cells and in derived OMVs, indicative of bacterial communication via lateral transfer of deiminated proteins.

\section{MATERIALS AND METHODS \\ Preparation of Outer Membrane Vesicles (OMVs) and Membrane Vesicles (MVs)}

E. coli (VCS257, Agilent, La Jolla, CA) and S. aureus subsp. aureus Rosenbach (ATCC 29247; CDC73-57501) cultures were grown for $24 \mathrm{~h}$ at $37^{\circ} \mathrm{C}$ (static culture). The growth phase before vesicle isolation was exponential, as assessed by optical density (OD600) before overnight incubation and for $4 \mathrm{~h}$ the following day, to ensure that bacteria were in log phase; the volume of the cultures was $20 \mathrm{ml}$. For OMV/MV-associated experiments, the bacterial growth medium (Luria-Bertani (LB) broth) and Dulbecco's phosphate buffered saline (DPBS)S were pre-treated before use by ultracentrifugation at 100,000 g (SW60Ti rotor, Beckmann L60 ultracentrifuge) for $24 \mathrm{~h}$, to ensure that the medium used was minimally contaminated with extracellular vesicles (EVs).

The OMV/MVs were isolated from the supernatant of the bacterial culture medium as follows: The supernatant was initially centrifuged once at $400 \mathrm{~g}$ (F-34-6-38 rotor, Eppendorf 5804 , U.S.A.) for $10 \mathrm{~min}$ to remove the cells. Thereafter, the supernatant was centrifuged at 4,000 $g$ (F-34-6-38 rotor, Eppendorf 5804) for $1 \mathrm{~h}$ at $4^{\circ} \mathrm{C}$ to remove cell debris. The resultant supernatant was then centrifuged at 100,000 $g$ (SW60Ti rotor, Beckmann L60 ultracentrifuge, Beckman Coulter, U.S.A.) for $1 \mathrm{~h}$ at $4^{\circ} \mathrm{C}$ for isolation of OMVs. The isolated OMV/MV 
pellet was then resuspended in Dulbecco's phosphate-buffered saline (DPBS; ultracentrifuged and sterile filtered using a $0.22 \mu \mathrm{m}$ filter) and filtered through an $0.45 \mu \mathrm{m}$ filter before the second ultracentrifigation step at $100,000 \mathrm{~g}$ for $1 \mathrm{~h}$ at $4^{\circ} \mathrm{C}$. The resulting $\mathrm{OMV} / \mathrm{MV}$ pellet was thereafter resuspended in 100 $\mu \mathrm{l}$ sterile filtered $(0.22 \mu \mathrm{m})$ DPBS and the isolated OMV/MV pellets were either used immediately, or stored at $-80^{\circ} \mathrm{C}$ for further experiments.

\section{Nanoparticle Tracking Analysis (NTA) of OMV/MV}

For NTA analysis, isolated OMV and MV pellets, respectively, prepared as described above, were resupended in $100 \mu \mathrm{l}$ sterile filtered DPBS and then diluted 1/200 before quantification to assess vesicle size, based on Brownian motion, using the Nanosight LM10, with a $405 \mathrm{~nm}$ diode laser (Malvern, U.K.). Numbers of particles per frame were kept at approximately 30 , and five individual $60 \mathrm{~s}$ videos were recorded using a sCMOS camera for each sample to create the respective size distribution histograms. OMVs/MVs were further characterized by transmission electron microscopy (TEM) and Western blotting as described below.

\section{Transmission Electron Microscopy Imaging}

A suspension of isolated OMVs/MVs $\left(1.4 \times 10^{8}\right.$ vesicles $\left./ \mathrm{ml}\right)$ was used for TEM imaging. Mesh copper grids were prepared with glow discharged carbon support films and $10 \mu \mathrm{l}$ of OMV/MV samples applied to the grid and incubated for $2 \mathrm{~min}$. The grids were then washed five times with $50 \mu \mathrm{l}$ of $1 \%$ aqueous uranyl acetate. The last drop was left to incubate on the grid for $1.5 \mathrm{~min}$ before being wicked off by torn filter paper. Grids were left to dry for $5 \mathrm{~min}$ before being viewed. Micrographs were taken with a JEOL JEM 1230 transmission electron microscope (JEOL, Japan) operated at $80 \mathrm{kV}$ at a range of magnification mainly around a magnification of 80,000-100,000. Digital images were recorded on a Morada CCD camera (EMSIS, Germany) and processed via iTEM (EMSIS, Germany).

\section{Western Blotting for Membrane Vesicle Characterization}

Protein was isolated from the OMV/MV pellets using Bacterial Protein Extraction Reagent (B-PER, ThermoFisher Scientific, U.K.), pipetting gently and shaking the pellets on ice for $2 \mathrm{~h}$, where after samples were centrifuged at $16,000 \mathrm{~g}$ at $4^{\circ} \mathrm{C}$ for $20 \mathrm{~min}$ and the resulting supernatant collected for protein analysis. Samples were electrophoresed under reducing conditions by SDS-PAGE on 4-20\% TGX gels (BioRad, U.K.), followed by semi-dry Western blotting. Membranes were blocked in 5\% BSA in TBS-T at RT for $1 \mathrm{~h}$. The membranes were incubated overnight at $4^{\circ} \mathrm{C}$ with the antiOmpC (Outer-membrane protein C antibody; orb6940, Biorbyt, U.K.; diluted 1/1,000 in TBS-T). The membranes were washed $3 \times 10 \mathrm{~min}$ in TBS-T, incubated for $1 \mathrm{~h}$ in anti-rabbit-HRP conjugated secondary antibody (BioRad, U.K.) at RT, followed by visualization using ECL (Amersham, U.K.) and the UVP BioDoc-ITTM System (U.K.).

\section{Immunoprecipitation (IP) and LC-MS/MS Analysis of Deiminated and PAD4 Bound Proteins From E. coli VCS257 Cells and Derived OMVs}

To determine the presence of deiminated/citrullinated proteins and PAD4 bound proteins from E. coli VCS257 and derived OMVs, protein extracts were prepared using Bacterial Protein Extraction Reagent (B-PER, ThermoFisher Scientific, U.K.), according to the manufacturer's instructions. In brief, bacterial cells and OMVs were centrifuged at $5,000 \mathrm{~g}$ for $10 \mathrm{~min}$ to obtain a pellet. Two microliter of lysozyme and $2 \mu \mathrm{L}$ of DNase I per $1 \mathrm{~mL}$ of B-PER Reagent was added along with EDTA-free protease inhibitors (ThermoFisher Scientific). Four $\mathrm{mL}$ of B-PER Reagent per gram of cell pellet was added. The suspension was pipetted up and down until it was homogeneous. The suspension was incubated for $10-15 \mathrm{~min}$ at room temperature. The lysate was centrifuged at $16,000 \mathrm{~g}$ for $5 \mathrm{~min}$ to separate soluble proteins from the insoluble proteins. Proteins were thereafter immunoprecipitated, using the Catch and Release ${ }^{\circledR}$ v2.0 Reversible Immunoprecipitation System (Merck, U.K.), according to the manufacturer's instructions, in conjunction with the pan-deimination F95 (MABN328, Merck) antibody (both for E. coli and derived OMVs) or the PAD4 (ab96758, Abcam) antibody (for E. coli cells only). The F95 pan-deimination specific antibody has been developed against a deca-citrullinated peptide and specifically detects proteins modified by citrullination (Nicholas and Whitaker, 2002). F95 or PAD4 bound proteins, respectively, were eluted from the columns according to the manufacturer's instructions (MERCK), using the supplied elution buffer (non-reducing or a reducing elution buffer, which was supplemented with $5 \%$ beta-mercapthoethanol) and thereafter further analyzed by Western blotting, under reducing conditions, and by liquid chromatography-mass spectrometry (LC-MS/MS).

\section{Western Blotting Analysis of Citrullinated/Deiminated Proteins From E. coli VCS257 Cells and Derived OMVs}

In order to compare protein profiles of deiminated proteins between E. coli and E. coli OMVs, total protein lysates and IP protein eluates were subjected to Western blot analysis. Briefly, samples were boiled for $5 \mathrm{~min}$ at $100^{\circ} \mathrm{C}$ in $2 \mathrm{x}$ Laemmli sample buffer (BioRad, U.K.). Protein ( $20 \mu \mathrm{g}$ per sample) was separated by SDS-PAGE using 4-20\% Mini-Protean TGX protein gels (BioRad, U.K) and transferred to nitrocellulose membranes. Even loading was assessed using Ponceau S staining (Sigma, U.K.) and membranes were then blocked in $5 \%$ bovine serum albumin (BSA) in Tris buffered saline with $0.1 \%$ Tween 20 (TBST) for $1 \mathrm{~h}$, followed by incubation at $4{ }^{\circ} \mathrm{C}$ overnight with the primary antibodies: pan-deimination antibody F95 (1:2,000; MABN328), PAD2 (1:1,000; ab50257), PAD3 (1:1,000; ab169479) and PAD4 (1:1,000; ab96758), respectively. Membranes were washed three times in TBS-T, incubated at room temperature for $1 \mathrm{~h}$ with HRP-conjugated secondary antibodies: anti-mouse IgM and anti-rabbit IgG, respectively (both 1:4,000; BioRad, U.K.), followed by six $10 \mathrm{~min}$ washes in TBS-T, before visualization 
using ECL (Amersham, U.K.) and the UVP BioDoc-IT ${ }^{\mathrm{TM}}$ System (U.K.).

\section{Liquid Chromatography-Mass Spectrometry (LC-MS/MS) Analysis}

For identification of deiminated/citrullinated proteins and PAD4 bound proteins, respectively, in E. coli cell lysate and OMV lysates, the F95 and PAD4 bound eluates were subjected to LC-MS/MS analysis, which was carried out at the Proteomics Service at the Barts Cancer Institute (Queen Mary University, U.K.). For identification of protein hits the peak list files were submitted to in-house Mascot (Matrix Science).

\section{Effects of PAD Inhibitors on Bacterial OMV/MV Release and Cell Viability}

E. coli and S. aureus were cultivated using EV-free MüellerHinton broth for $24 \mathrm{~h}$. Culture condition were as follows: An inoculate of $0.1 \mathrm{ml}$ of bacteria were grown at exponential phase overnight, as assessed by OD600; the volume of the cultures was $20 \mathrm{ml}$. The cells were washed using DPBS at 4,000 g for $10 \mathrm{~min}$ and seeded in triplicate in micro centrifuge tubes. The PAD inhibitors were added in triplicates and incubated for $1 \mathrm{~h}$ at $37^{\circ} \mathrm{C}$ as follows: PAD2 inhibitor AMF30a $(5 \mu \mathrm{M})$, PAD4 inhibitor, GSK199 $(10 \mu \mathrm{M})$, pan-PAD inhibitor Cl-amidine $(50 \mu \mathrm{M})$, and $\mathrm{BB}-\mathrm{Cl}$-amidine $(5 \mu \mathrm{M})$. Cell viability of bacteria in the presence of the different PAD inhibitors was assessed by counting the number (no) of surviving bacterial colonies on the plates. The no. of colonies (viable cells), inoculating volume and dilution factor of the bacterial culture used was used to calculate the viable cells in colony forming unit $(\mathrm{cfu} / \mathrm{ml})(\mathrm{cfu} / \mathrm{ml}=$ (no. of colonies $\mathrm{x}$ dilution factor $) /$ volume of culture plate). OMV/MV isolation following treatment was carried out as described above and changes in OMV/MV release were assessed by quantifying numbers of OMVs/MVs by NTA analysis using the Nanosight LM10 as described above. The experiment was repeated three times and replicate histograms were averaged.

\section{Disc Diffusion Test}

E. coli VCS257 and S. aureus subsp. aureus Rosenbach nutrient agar plates were prepared and sterile paper disks were soaked in the PAD inhibitors at the same concentrations as before. Culture medium was $10 \mathrm{ml}, \log$ growth phase of bacteria was assessed by OD600, and the inoculum concentration was $0.1 \mathrm{ml}$. Discs were impregnated with the antibiotics (all from Sigma-Aldrich) at the following concentrations: colistin $(10 \mu \mathrm{g} / \mathrm{ml})$, rifampicin (15 $\mu \mathrm{g} / \mathrm{ml})$, erythromycin $(15 \mu \mathrm{g} / \mathrm{ml})$, kanamycin $(1,000 \mu \mathrm{g} / \mathrm{ml})$, and vancomycin $(5 \mu \mathrm{g} / \mathrm{ml})$. The inhibitor discs were placed in the middle of the agar plates, while the antibiotic discs were placed equi-distant to the respective inhibitor discs to be tested. The Kirby-Bauer test was used to assess the zone of inhibition after 24 h. Supplementary Figure 4 shows the agar plates containing the disks, following completion of the test.

\section{MIC Measurement of Colistin and Vancomycin in E. coli VCS257 and}

\section{S. aureus subsp. aureus Rosenbach}

MIC values for colistin and vancomycin were tested for E. coli and $S$. aureus, respectively. E. coli and S. aureus suspensions were prepared in Müller Hinton Broth according to Iqbal et al. (2013). For E. coli, the concentration of colistin was based on previously published MIC values for colistin, ranging between 2 and $16 \mu \mathrm{g} / \mathrm{ml}$ (Moskowitz et al., 2010; Rojas et al., 2017), and here this range was further expanded between $0.015 \mu \mathrm{g} / \mathrm{ml}$ to $64 \mu \mathrm{g} / \mathrm{ml}$. MIC values for vancomycin have previously been recorded in the range of 1.5-2 $\mu \mathrm{g} / \mathrm{ml}$ (Maclayton et al., 2006; Kshetry et al., 2016; Goldstein et al., 2018) and in some studies a MIC value of $8 \mu \mathrm{g} / \mathrm{ml}$ and higher has been reported (Alam et al., 2014; Lepe et al., 2014). Therefore, for $S$. aureus a MIC confirmation test starting from a concentration of $8 \mu \mathrm{g} / \mathrm{ml}$ was carried out here and thereafter the MIC was considered accordingly. The doubling dilution method was used to obtain triplicates of concentrations used for the antibiotics and a triplicate of control omitting antibiotic was also prepared. The plates were incubated overnight at $37^{\circ} \mathrm{C}$ and the MIC values of antibiotic treated control wells were compared to wells where PAD inhibitors were applied in combination with the antibiotics.

\section{Statistical Analysis}

The histograms and graphs were prepared and statistical analysis was performed using GraphPad Prism version 8 (GraphPad Software, San Diego, U.S.A.). One-way ANOVA and $t$-test analysis were performed, followed by Tukey's post-hoc analysis. Significant differences were considered as $p \leq 0.05$ and histograms represent mean of data, with error bars representing standard error of mean (SEM).

\section{RESULTS}

\section{Characterization of Bacterial OMVs/MVs}

A poly-dispersed population of OMVs was verified by nanoparticle tracking (NTA) analysis, with the majority of vesicles released in the $20-300 \mathrm{~nm}$ range for E. coli VCS257, and similarly in the $37-300 \mathrm{~nm}$ range for $S$. aureus subsp. aureus Rosenbach (Figures 1A1, 2). This was further confirmed by transmission electron microscopy, assessing overall morphology and providing average size estimations (Figures 1B1, 2). Morphological analysis by TEM revealed OMVs, including with inner and outer membranes visible, for E. coli (Figure 1B1) and typical MVs for S. aureus (Figure 1B2). Western blotting verified the presence of the OMV-specific marker OmpC (Figure 1C). Changes in OMV size distribution after PAD-inhibitor treatment in E. coli was reflected in a change in NTA profile as shown in Figures 1D-G and further discussed below.

\section{PAD Inhibitors Inhibit OMV Release in the Gram-Negative Bacterium E. coli VCS257}

Effects of the various PAD inhibitors on OMV release in E. coli are shown in Figure 2. The PAD4-specific inhibitor GSK199 

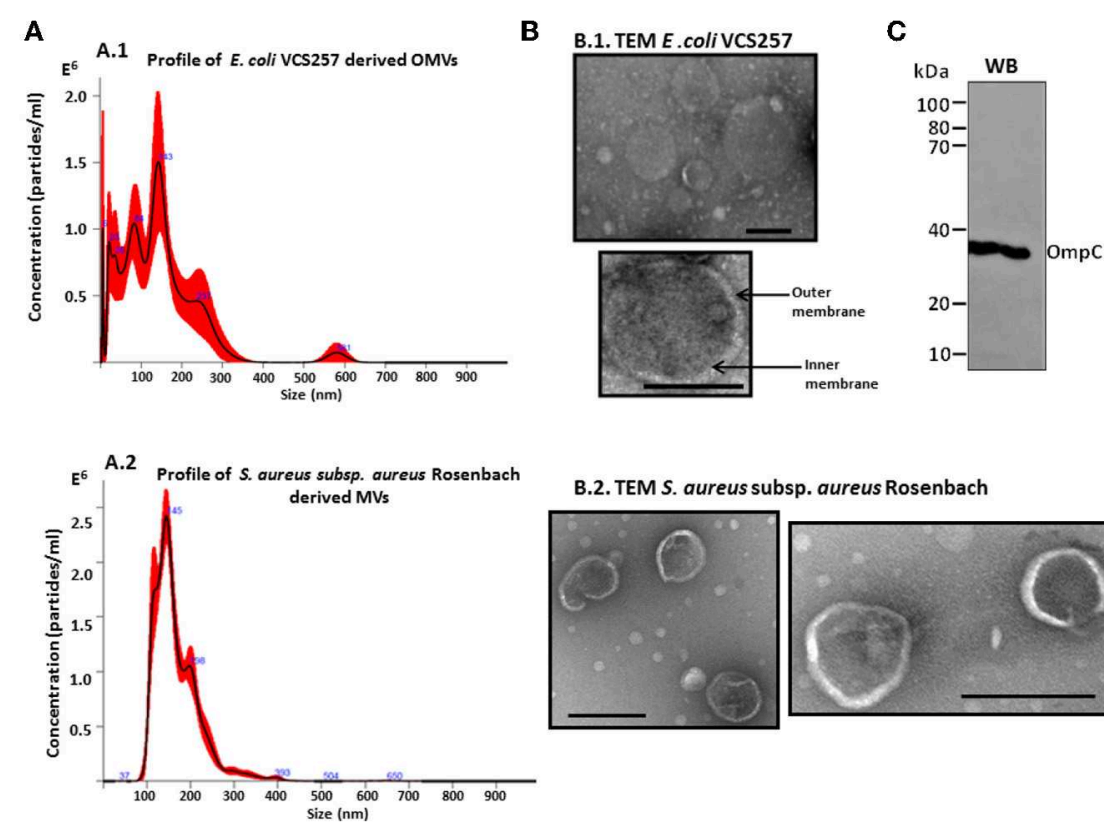

B.2. TEM S. aureus subsp. aureus Rosenbach

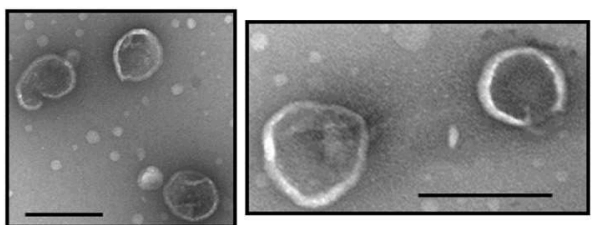

D

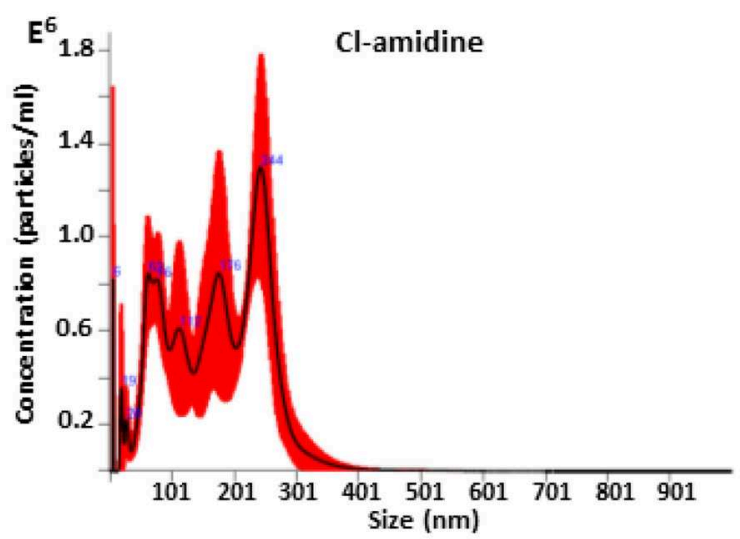

F

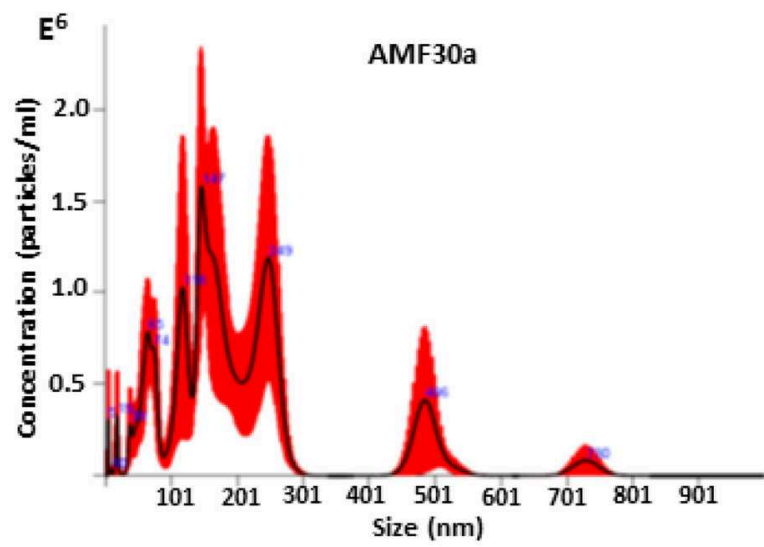

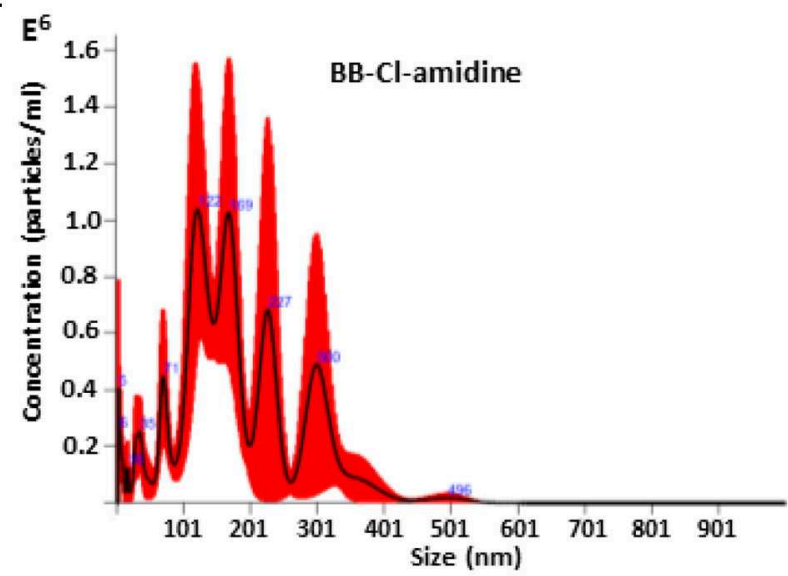

G

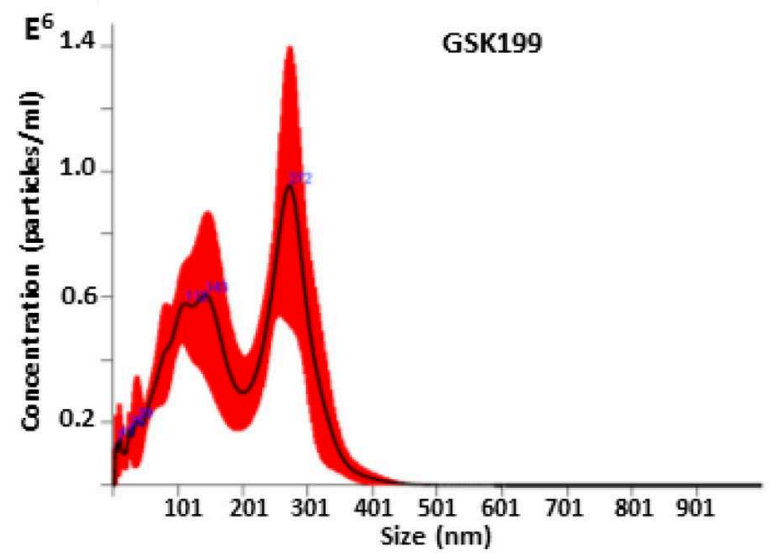

FIGURE 1 | Characterization of E. coli VCS257 OMVs and S. aureus subsp. aureus Rosenbach MVs using NTA, TEM and Western blotting analysis. (A) NTA curves, obtained by Nanosight analysis, showing OMVs released from E. coli (A1) and S. aureus (A2) under standard conditions; (B) Negative stain TEM micrographs of E. coli OMVs (B1) show the presence of a poly-dispersed sample ranging in size from mainly $20 \mathrm{~nm}$ to $320 \mathrm{~nm}$ (scale bars represent $200 \mathrm{~nm}$ ), including vesicles showing 
FIGURE 1 | inner and outer membranes for E.coli VCS257 OMVs (B1) and MVs from S. aureus subsp. aureus Rosenbach (B2). (C) OMV-specific marker OmpC verified by Western blotting. (D-G) NTA profiles of OMVs released from E. coli VCS257 following PAD inhibitor treatment. OMV release profile from E. coli treated for $1 \mathrm{~h}$ with PAD inhibitors as follows: (D) Cl-amidine (first generation pan-PAD inhibitor; $50 \mu \mathrm{M}$ ); (E) BB-Cl-amidine (second generation pan-PAD inhibitor; $5 \mu \mathrm{M}$ ); (F) AMF30a (PAD2 inhibitor; $5 \mu$ M); (G) GSK199 (PAD4 inhibitor; $10 \mu \mathrm{M})$.

showed most potent OMV inhibition with a $66.4 \%$ reduction in OMV release $(p=0.0001)$, but also most significantly affected cell viability $(23.9 \%$ reduction, $p=0.0008)$. $\mathrm{BB}-\mathrm{Cl}$-amidine was the second most potent inhibitor with a $53.8 \%$ reduction in OMV release $(p<0.0001)$ and a reduction, albeit non-significant $(p$ $=0.1351)$, of $19.3 \%$ in cell viability, as measured by CFU. Clamidine resulted in a $42.4 \%$ inhibition of OMV release $(p=$ $0.0001)$ and an $18.2 \%$ decrease in cell viability $(p=0.0111)$. The PAD2-specific inhibitor AMF30a was less effective with a $28.2 \%$ reduction in OMV release $(p=0.0116)$ and caused a $14.7 \%$ reduction in cell viability ( $p=0.0283$ ) (Figure 2B). Furthermore, in addition to reduced total OMV numbers released after PAD inhibitor treatment, the following changes in OMV profiles were observed by NTA analysis: Cl-amidine treated E. coli released OMVs in the size range $20-400 \mathrm{~nm}, \mathrm{BB}-\mathrm{Cl}$-amidine treated cells showed OMV release in the $20-500 \mathrm{~nm}$ size range, while AMF30a (PAD2 inhibitor) treatment resulted in an additional notable peak of OMVs at $501 \mathrm{~nm}$ and a second smaller peak at $701 \mathrm{~nm}$. GSK199 (PAD4 inhibitor) treatment resulted in an OMV release profile of $20-400 \mathrm{~nm}$, similar to that for $\mathrm{Cl}$-amidine (Figures 1D-G).

\section{PAD Inhibitors Inhibit Membrane Vesicle (MV) Release in S. aureus subsp. aureus Rosenbach}

The same range of PAD inhibitors as used with E. coli was used to examine the effect on membrane vesicle (MV) release from a Gram-positive bacterium, S. aureus subsp. aureus Rosenbach (Figure 2C). PAD4-specific inhibitor GSK199 resulted in the highest inhibition of MV release, with $22.5 \%$ reduction ( $p$ $=0.0018$ ), while PAD2 inhibitor AMF30a showed only 3.4\% reduction in OMV release $(p=0.0606)$. First generation panPAD inhibitor $\mathrm{Cl}$-amidine resulted in a $12.5 \%$ inhibition of $\mathrm{MV}$ release $(p=0.0016)$, and also had the lowest negative impact on $S$. aureus cell viability $(3.3 \%, p=0.0835$; Figure $2 \mathrm{D})$, while second generation pan-PAD inhibitor $\mathrm{BB}-\mathrm{Cl}$-amidine showed 7.6\% $\mathrm{MV}$ inhibition $(p=0.0061)$ (Figures 2C,D).

\section{Phylogenetic Reconstruction of E. coli and S. aureus PAD/AD}

Two well supported clades were formed within the Neighborjoining phylogeny (Figure 3) based on multiple sequence alignment of the whole amino acid sequences (using Clustal Omega), suggesting that E. coli PAD/AD (arginine deiminase RRM86073.1) is most closely related to human PAD2 (Figure 3A). The E. coli $\mathrm{PAD} / \mathrm{AD}$ has a shorter, 406 amino acid (aa) sequence (arginine deiminase EDV68547.1), compared to human PAD2 (NP031391), PAD3 (AIC56498), and PAD4 (AIC56076), which are 665, 663, and 664 aa, respectively. Various single, fully conserved residues are found, while some conservation of similarity between E. coli PAD/AD with human PAD2 and PAD3 is visible that scores $>0.5$ in the Gonner PAM matrix (Supplementary Figure 1). For S. aureus, two wellsupported clades were also formed within the Neighbor-joining phylogeny (Figure 3B), suggesting that $\mathrm{S}$. aureus $\mathrm{PAD} / \mathrm{AD}$ (arginine deiminase BBA25170) is also most closely related to human $\mathrm{PAD} 2$. The $\mathrm{S}$. aureus bacterial $\mathrm{PAD} / \mathrm{AD}$ has a shorter, 411 aa sequence (BBA25170), similar to that seen for E. coli $\mathrm{PAD} / \mathrm{AD}$, compared to the human PAD2, PAD3, and PAD4 isozymes, which are approximately 664 aa. Various single, fully conserved residues are found, while some conservation of similarity between S. aureus PAD/AD to human PAD2 and PAD3 is visible that scores $>0.5$ in the Gonner PAM matrix (Supplementary Figure 2).

\section{Detection of PAD/AD Protein and Citrullinated/Deiminated Protein Products in E. coli VCS257}

Using Western blotting analysis, E. coli cell and E. coli OMV protein extracts were assessed for total deiminated proteins, using the anti-peptidyl-citrulline F95 antibody (MABN328, Merck, U.K.), as well as for cross-reactivity with human PAD2 (ab50257), PAD3 (ab169479), and PAD4 (ab96758) antibodies (Figure 4). For total deiminated proteins (F95), bands in the size range of $15-120 \mathrm{kDa}$ were revealed in both E. coli cells and derived OMVs (Figure 4A). The presence of a PAD/AD-like protein was verified in E. coli and derived OMVs, by the detection of an expected band at $40-50 \mathrm{kDa}$, representative of a bacterial PAD/AD (Figure 4B).

\section{Immunoprecipitation of Deiminated Proteins From E. coli VCS257 and Derived OMVs}

Deiminated proteins from E. coli and derived OMVs were immunoprecipitated using the Catch and Release ${ }^{\circledR}$ v2.0 Reversible Immunoprecipitation System (Merck, U.K.) according to the manufacturer's instructions and the anti-peptidyl-citrulline F95 antibody (MABN328, Merck) (Figures 4C,D and Supplementary Figure 3). As the PAD4 inhibitor GSK199 was here found to be the most effective OMV inhibitor (Figure 2A), immunoprecipitation using the PAD4 antibody was also carried out on E. coli cell protein extracts, for identification of putative PAD4 bound proteins (Figure 4 and Supplementary Figure 3). A range of F95 enriched bands was seen in both E. coli and OMV samples (Figure 4C). In addition, the PAD4 enriched eluate showed an F95 positive band in the expected size range of an E. coli $\mathrm{PAD} / \mathrm{AD}$ at $45 \mathrm{kDa}$ (Figure 4C, lane 6, arrow), thus indicating that $E$. coli $\mathrm{PAD} / \mathrm{AD}$ itself may also be deiminated. This band was more prominent when the PAD4 antibody was used for immunoprecipitation from the E. coli protein lysate, showing a very strong band just below $50 \mathrm{kDa}$ 


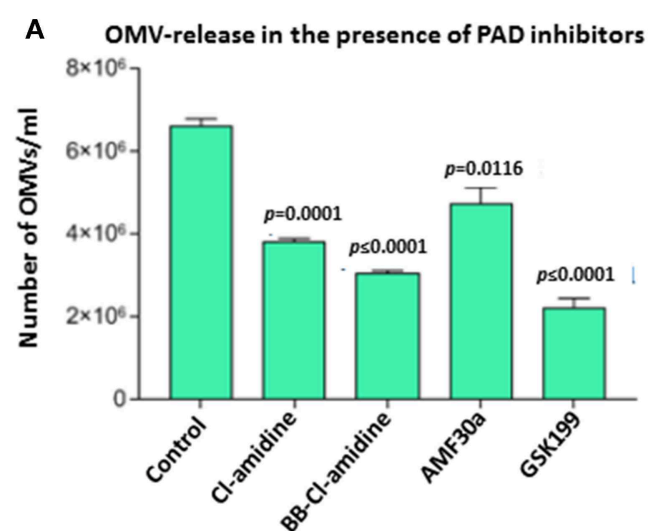

C

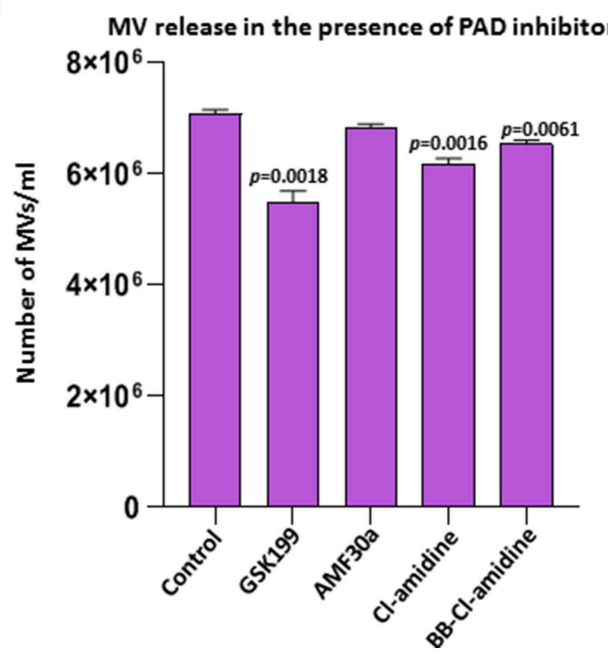

B E. coli growth in the presence of PAD inhibitors

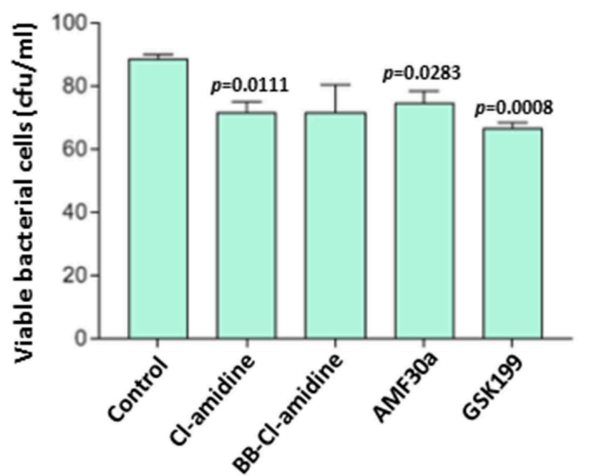

D

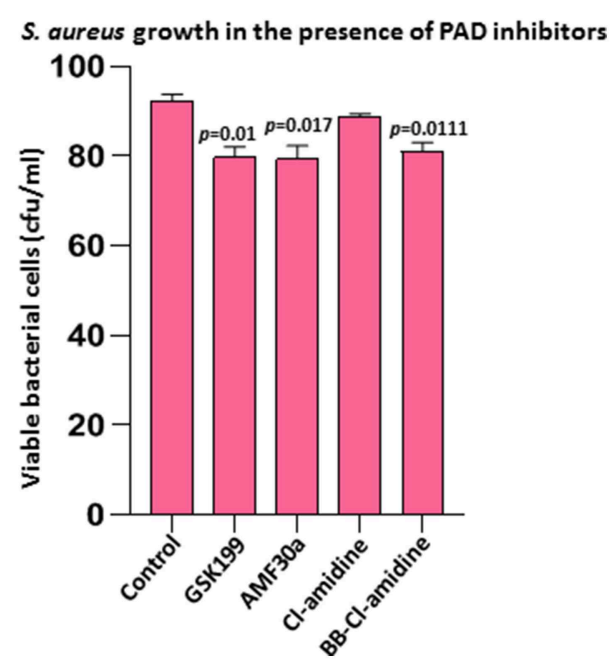

FIGURE 2 | Effects of PAD inhibitors on OMV release from E. coli VCS257 and MV release from S. aureus subsp. aureus Rosenbach. (A) All PAD inhibitors showed significant OMV inhibition in E. coli compared to untreated controls. PAD4 inhibitor GSK199 and second generation pan-PAD inhibitor BB-Cl-amidine were the strongest inhibitors of OMV release. The PAD2-specific inhibitor AMF30a was less effective. (B) E. coli viability after $24 \mathrm{~h}$ PAD inhibitor treatment, represented as CFU. (C) PAD4 inhibitor GSK199 was the most effective MV inhibitor in S. aureus, reducing MV release by $22.5 \%$. (D) S. aureus viability, represented as CFU, after $24 \mathrm{~h}$ treatment with PAD inhibitors is shown. The experiment was repeated thrice and the data presented are mean \pm SEM of the results; exact $p$-values are indicated. Concentration of PAD-inhibitors used was as follows: PAD2 inhibitor AMF30a $(5 \mu \mathrm{M})$, PAD4 inhibitor, GSK199 (10 $\mu \mathrm{M})$, pan-PAD inhibitors Cl-amidine (50 $\mu \mathrm{M})$ and BB-Cl-amidine $(5 \mu \mathrm{M})$.

A

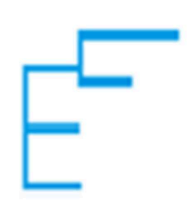

E. coli- PAD/AD Homo sapiens- PADI2

Homo sapiens- PADI3

Homo sapiens- PADI4
B

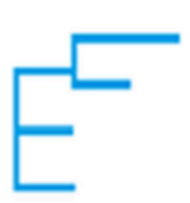

S. aureus - PAD/AD

Homo sapiens- PADI2 Homo sapiens- PADI3 Homo sapiens- PADI4

\section{Clade 1}

Clade 2

FIGURE 3 | Neighbor joining tree. The phylogenetic clustering of $E$. coli (A) and S. aureus (B) PAD/AD, respectively is shown. The evolutionary analysis was inferred using the Neighbor-Joining method under the conditions of the Poisson distance correction model in MEGA6. Bootstrap values $>50$ based on 1,000 replicates are shown as nodal support. Clade 1 contains E. coli (GenBank: EDV68547.1) PAD/AD and Clade 2 contains human PAD2 (GenBank:NP031391), PAD3 (GenBank: AlC56498) and PAD4 (GenBank: AlC56076).

(Figure 4D, lanes 5-6). When testing the PAD4 bound eluate with the F95 deimination antibody, several additional positive bands were detected and may possibly represent deiminated proteins co-immunoprecipitating with the PAD4 antibody (Figure 4C; lanes 5 and 6). The F95 eluate from OMVs though also showed a reaction with the PAD4 antibody (Figure 4D; 


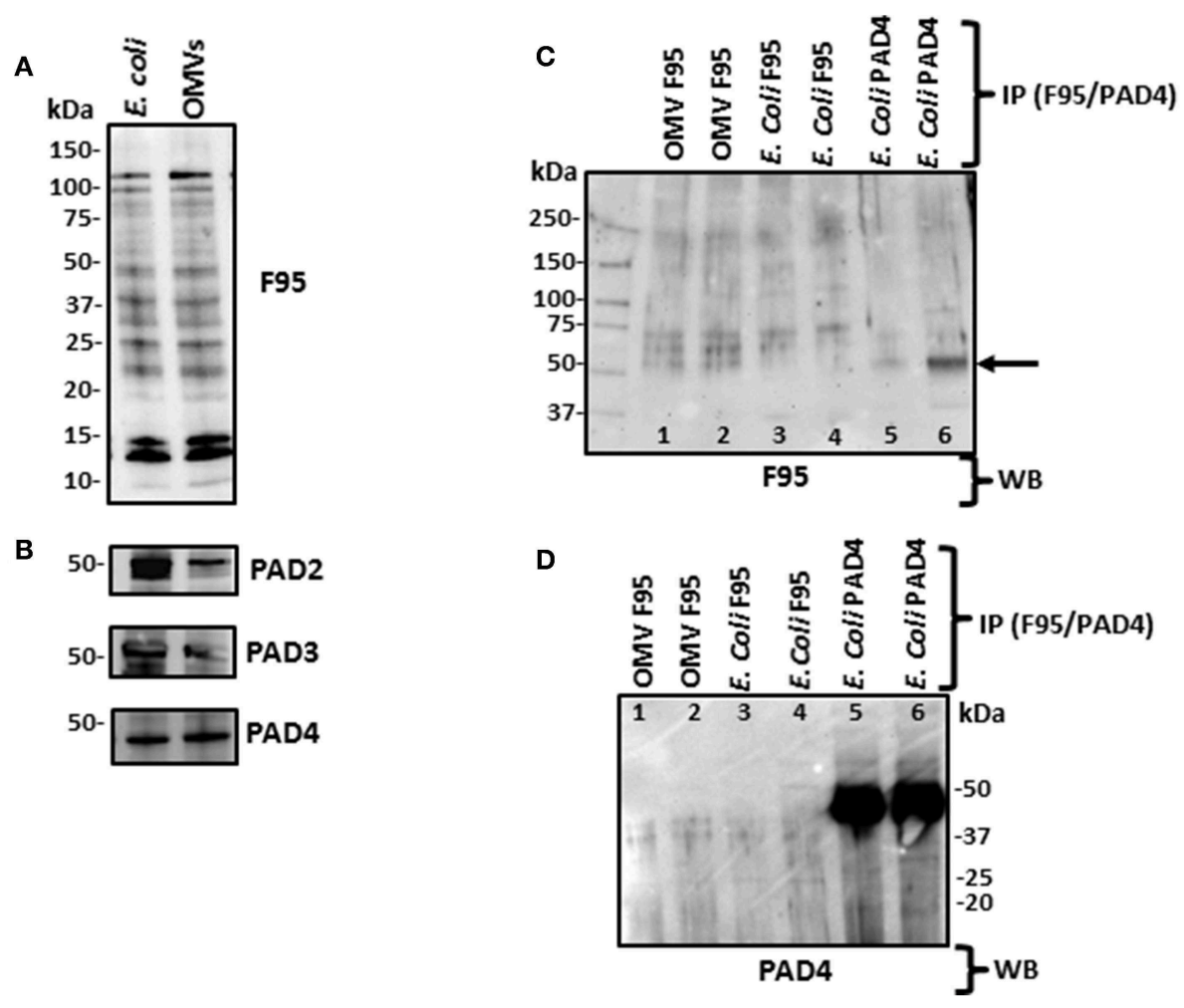

FIGURE 4 | Western blotting of total deiminated proteins and PAD/AD in E. coli VCS257 cells and derived OMVs. (A) E. coli and derived OMVs were analyzed for total deiminated proteins (F95) as well as for cross-reactivity with human PAD2, PAD3 and PAD4. Bands in the size range of 15-120 kDa were revealed for the pan-deimination antibody (F95). (B) The human PAD2, 3 and 4 antibodies reacted with a band of 40-50 kDa as expected for a bacterial PAD/AD homolog. Lane 1, E. coli total protein extract; Lane 2, E. coli OMV protein extract. (C,D) Immunoprecipitated deiminated proteins (F95) and PAD4 bound proteins from E. coli VCS257 and derived OMVs. IP was performed on E. coli total protein and E. coli derived OMVs, using F95 and PAD4 antibodies, respectively. (C) Immunoprecipitated fractions (F95 enriched and PAD4 bound, respectively) were tested with the pan-deimination F95 antibody. A range of deiminated/citrullinated proteins was observed in E. coli cells and derived OMVs. Lanes 5 and 6 indicate a deiminated band at $50 \mathrm{kDa}$ corresponding to E. coli PAD/AD (arrow) For lanes 5 and 6 the F95 enriched eluate was eluted using non-reducing and reducing elution buffer, respectively, and both F95-bound eluates obtained were thereafter run under reducing conditions in the gel. (D) The same fractions were tested with the PAD4 antibody. Prominent bands around the $50 \mathrm{kDa}$ region (lanes 5-6) correspond to a predicted size of E. coli PAD/AD. Faint bands of similar sizes are also observed in the OMV F95-enriched samples (lanes 1-2) which may suggest the presence of a PAD/AD which is deiminated in both E. coli and derived OMVs. The protein standard is indicated in kDa on all blots. For identification of protein hits as assessed by LC-MS/MS for the F95 and PAD4 bound eluates, see Tables 1, 2.

lanes 3 and 4), and therefore may indicate a deiminated PAD/AD and further deiminated proteins bound to the PAD/AD in E. coli derived OMVs. Such auto-deimination of the bacterial PAD/AD will though require further investigation to be fully confirmed.

\section{Liquid Chromatography-Mass Spectrometry (LC-MS/MS) Analysis of Deiminated Proteins From E. coli VCS257 and Derived OMVs}

Immunoprecipitated proteins (F95 enriched and PAD4 bound) from E. coli cells and derived OMVs were analyzed by LCMS/MS (Figures 5, 6 and Tables 1, 2). Nine deiminated proteins were identified in the F95 enriched E. coli OMV protein sample (Figures 5, 6A). The 30s ribosomal protein S15 was unique to OMVs. As threonine-tRNA ligase $(t h r S)$, has not been reported in E. coli OMVs before, STRING (Search Tool for the Retrieval of Interacting Genes/Proteins) analysis (https://string-db.org/) was carried out to assess if thrS is interconnected with the other proteins in the OMV associated proteins (Figure 6B). This showed five of the nine proteins to be associated with each other, at least through text mining. Furthermore, the E. coli $\mathrm{OMV}$-associated thrS is co-expressed with 30s ribosomal protein $\mathrm{S} 15$ (rpsO), 30s ribosomal protein $\mathrm{S} 4$ ( $r p s D$ ) and $50 \mathrm{~S}$ ribosomal protein $\mathrm{L} 22(r p l Y)$, as well as being experimentally determined to interact with $r p l Y$ (Figure 6B).

Table 1 lists proteins identified in E. coli cell samples that were unique in F95 enriched eluates. Table 2A lists proteins that were identified in the PAD4 enriched eluates from E. coli cells, indicative of PAD4 bound proteins. Table 2B summarizes common proteins identified in all three eluates (F95 enriched eluate from E. coli cells, F95 enriched eluate from OMVs, PAD4 enriched eluate from $E$. coli cells); proteins are shown that had two or more peptides identified and a protein score of $>50$. 


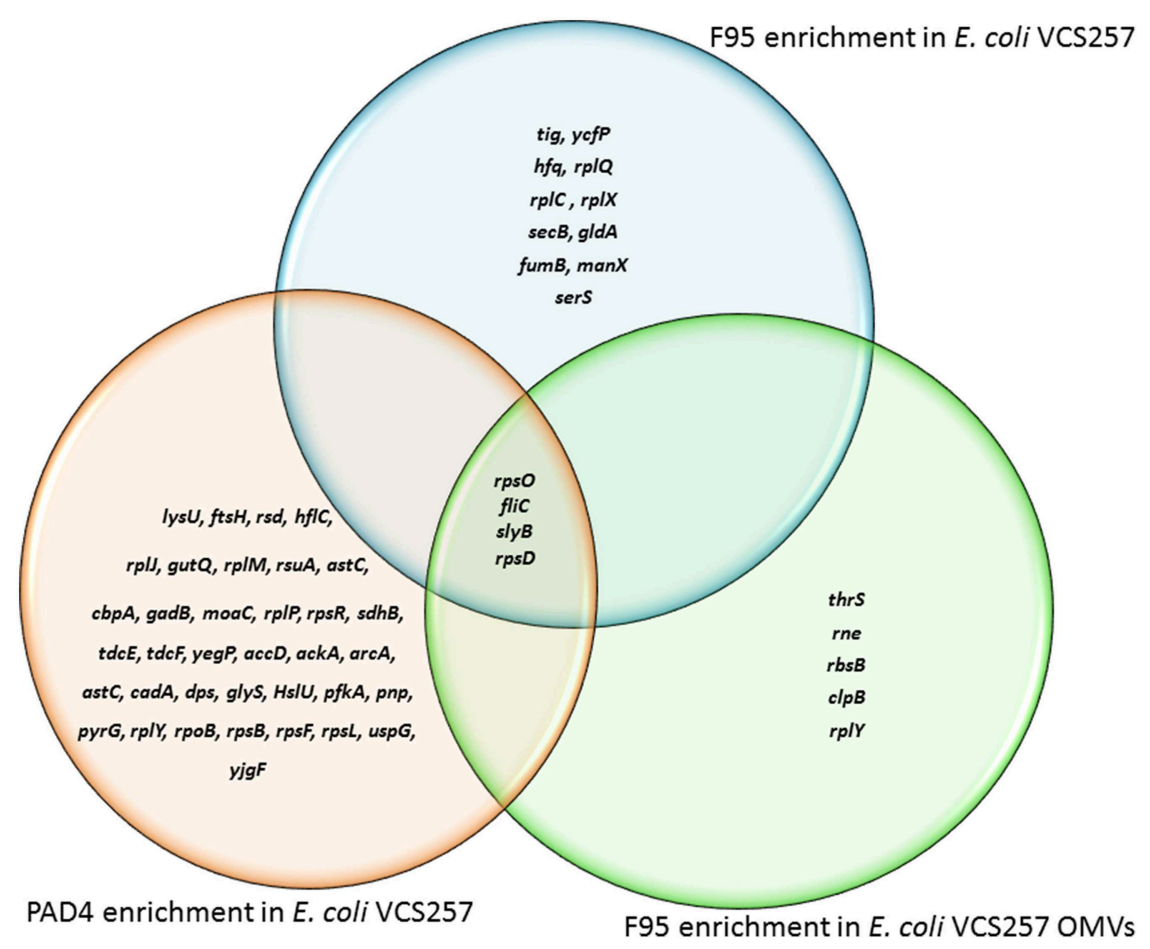

FIGURE 5 | Deiminated proteins and PAD4 bound proteins identified in E. coli VCS257 cells and derived OMVs. The Venn diagram shows F95 enriched proteins identified from E. coli cells and E. coli OMVs, as well as PAD4 bound proteins identified from E. coli cells. Four proteins were common to all three eluates (for further details on protein identification see Tables 1, 2).

\section{PAD Inhibitor Treatment Enhances Antibiotic Sensitivity of $E$. coli VCS257}

Kanamycin was the most effective antibiotic against E. coli in the absence of PAD inhibitors (Figure 7A). In the presence of PAD inhibitors, GSK199 most significantly enhanced the effects of erythromycin, measured as a percentage increase in the zone of inhibition on the lawn of $E$. coli, by $88.9 \%(p=0.0025)$; that of rifampicin by $56.7 \%(p=0.0561)$ and that of colistin by $14.6 \%$ ( $p=0.2495)$. BB-Cl-amidine was most effective when used in combination with rifampicin, increasing the zone of inhibition by $106.45 \%(p=0.0025)$ and that of kanamycin by $65.6 \%$ ( $p=0.0186)$. Cl-amidine caused enhancement of antibiotic sensitivity in combination with rifampicin $(43.8 \%$; $p$ $=0.045)$, erythromycin (35.6\%; $p=0.0572)$, and kanamycin (38.8\%; $p=0.0390)$, compared to antibiotic alone (Figure 8). AMF30a was not effective in sensitizing $E$. coli to any of the antibiotics tested (see Supplementary Figure 4A, showing the agar plates). Importantly, there were no zones of inhibition seen in the agar plates which were only treated with the inhibitor discs, thus ruling out any inhibition on bacterial growth in the absence of antibiotics (Supplementary Figure 4B).

\section{PAD Inhibitors Enhance Antibiotic Sensitivity of $S$. aureus subsp. aureus Rosenbach}

PAD inhibitors significantly enhanced antibiotic effectivity against $S$. aureus (Figure 7B). For erythromycin, BB-Cl-amidine significantly enhanced antibacterial effects, by $18.2 \%(p=$ 0.0234 ). For vancomycin, GSK199 was most effective, with a $69.3 \%$ increase in antibiotic effectivity $(p=0.0250)$, while Clamidine was also significant $(42.7 \%, p=0.0354)$. (Figure 7B). For rifampicin, GSK199 and Cl-amidine significantly increased the zone of inhibition $(10.1 \% ; p=0.0202)$ and $6.4 \% ; p=$ 0.0239 , respectively). The antibacterial effects of kanamycin were also significantly increased by both Cl-amidine and BBCl-amidine by $20.8 \%(p=0.0055)$ and $28.9 \%$; $(p=0.0101)$, respectively. For colistin, $\mathrm{Cl}$-amidine increased the zone of inhibition by $21.5 \%(p=0.0444)$. There were no zones of inhibition seen in the agar plates treated with the PAD inhibitor discs alone, indicating no effect on bacterial growth (Supplementary Figures 4C,D).

\section{PAD Inhibitors Decrease MIC Value of Colistin Against E. coli VCS257}

As the minimum inhibitory concentration (MIC) value of colistin against Gram-negative bacteria has been inconsistently reported in the literature it was further investigated here (Figure 8A). BB-Cl-amidine and $\mathrm{Cl}$-amidine resulted in 91.6\% $(p=0.0001)$ and $87.4 \%(p=0.0002)$ reduction in MIC, respectively, while GSK199 lowered the MIC by $76 \%(p=0.0004)$ (Figure 8A). There were no zones of inhibition seen in the plates which were only treated with the inhibitor discs, indicating no bactericidal effect due to inhibitors alone. 
A

\begin{tabular}{|c|c|c|c|c|}
\hline UniProt ID & Protein name & Gene name & MS2 Intensity & Score $(p<0.05)$ \\
\hline Q1R6H3 & 30 S ribosomal protein $\$ 15$ & $\operatorname{rps} O$ & 67181.14 & 585.62 \\
\hline P04949 & Flagellin & flic & 9488.724 & 653.24 \\
\hline P0A906 & Outer membrane lipoprotein & slyB & 10565.21 & 632.79 \\
\hline Q1R636 & 30 S ribosomal protein \$4 & $\operatorname{rps} D$ & 3554.363 & 289.35 \\
\hline B7L6J2 & Threonine--tRNA ligase & thrs & 8718.552 & 371.78 \\
\hline P21513 & Ribonuclease E & me & 8574.855 & 369.58 \\
\hline P02925 & D-ribose-binding periplasmic protein & $\operatorname{rbs} B$ & 6973.666 & 270.86 \\
\hline P63285 & Chaperone protein ClpB & $d p B$ & 30537.26 & 227.63 \\
\hline B5YWX8 & $50 S$ ribosomal protein $\mathrm{L} 25$ & $r p / Y$ & 4326.5 & 51.12 \\
\hline
\end{tabular}

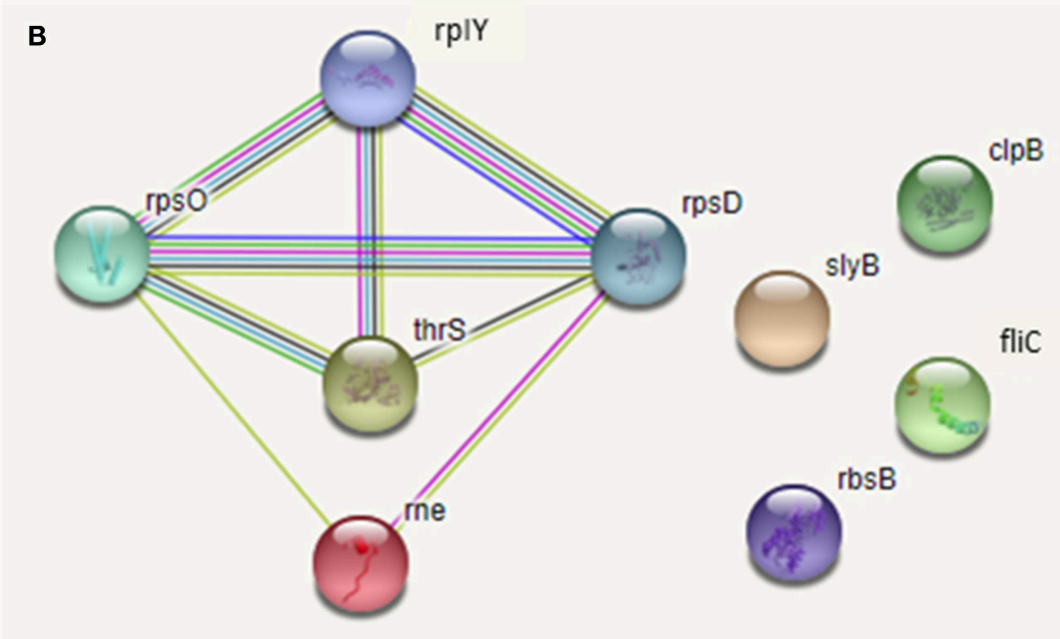

Known interactions

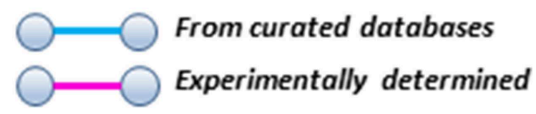

Predicted interactions

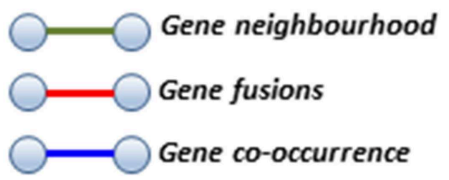

Others

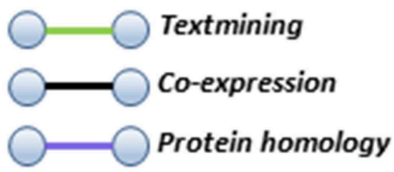

FIGURE 6 | Deiminated proteins in E. coli VCS257 OMVs. Deiminated proteins were isolated by immunoprecipitation using the F95 antibody and analyzed by LC-MS/MS. (A). All deiminated proteins identified in the OMV sample, with a score $>50$ are listed. lons score is $-10^{\star}$ Log $(P)$, where $P$ is the probability that the observed match is a random event. Individual ions scores $>16$ indicated identity or extensive homology $(p<0.05)$. Protein scores were derived from ions scores as a non-probabilistic basis for ranking protein hits. Cut-off was set at lons score 20 . Values with 2 or more peptides per protein and a score of $>50$ were considered.

(B). String analysis of the deiminated proteins identified in E. coli OMVs. Out of 9 proteins, 5 were associated with each other, at least through text mining.

\section{PAD Inhibitors Decrease MIC Value of Vancomycin Against S. aureus subsp. aureus Rosenbach}

The MIC value of vancomycin against $S$. aureus has been inconsistently reported in the literature and was thus investigated further. Figure 8B shows the effect of the most effective MVinhibiting PAD inhibitors on the MIC of vancomycin; Clamidine showed a $62.5 \%$ reduction $(p=0.0022)$ while GSK199 lowered MIC by $25 \%(p=0.0161)$ (Figure $8 B$ ). There was no effect on MIC of colistin in the presence of inhibitors alone.

\section{DISCUSSION}

For analysis of bacterial OMV/MVs in this study, isolation and quantification approaches using ultracentrifugation and
NTA analysis were used, similar as performed by other groups (McCaig et al., 2013; Klimentova and Stulik, 2015; Roier et al., 2016). OMVs have previously been reported to fall mainly in the size range 10-300 $\mathrm{nm}$ (Kulkarni et al., 2015; Huang et al., 2016), and similar profiles were observed here. OMVs were also further characterized morphologically using TEM, and by Western blotting analysis using the outer membrane specific marker, OmpC (Figure 1). Furthermore, some change in OMV profile was observed in response to PAD inhibitor treatment, and this varied between inhibitors used, showing a change in shift of vesicle size populations after treatment with the different PAD inhibitors.

Here, an E. coli VCS257 citrullinome was identified for the first time, using F95 enrichment and LC-MS/MS analysis, confirming the presence of deiminated/citrullinated proteins in E. coli cells and E. coli derived OMVs. In bacteria, studies on PAD/AD 
TABLE 1 | Deiminated proteins identified by F95 enrichment in E. coli VCS257cells.

\begin{tabular}{|c|c|c|c|c|}
\hline UniProt ID & Protein name & Abbreviation & MS2 Intensity & Score $(p<0.05)^{a}$ \\
\hline B7MQF2 & Trigger factor & tig & 81193 & 192.72 \\
\hline $\mathrm{B} 7 \mathrm{NKH1}$ & $\begin{array}{l}\text { UPF0227 protein } \\
\text { YcfP }\end{array}$ & $y c f P$ & 11941 & 166.86 \\
\hline B7MSJ0 & $\begin{array}{l}\text { RNA-binding } \\
\text { protein } \mathrm{Hfq}\end{array}$ & $h f q$ & 256917 & 132.47 \\
\hline Q1R638 & $\begin{array}{l}50 S \text { ribosomal } \\
\text { protein L17 }\end{array}$ & $r p / Q$ & 126430 & 128.85 \\
\hline Q1R602 & $\begin{array}{l}50 S \text { ribosomal } \\
\text { protein L3 }\end{array}$ & rp/C & 69461 & 254.77 \\
\hline Q1R619 & $\begin{array}{l}50 S \text { ribosomal } \\
\text { protein L24 }\end{array}$ & $r p / X$ & 6484.4 & 75.48 \\
\hline B7N255 & $\begin{array}{l}\text { Protein-export } \\
\text { protein SecB }\end{array}$ & $\sec B$ & 136512 & 77.044 \\
\hline P14407 & $\begin{array}{l}\text { Fumarate } \\
\text { hydratase class } \\
\text { I, anaerobic }\end{array}$ & fumB & 15233 & 78.27 \\
\hline P0A9S6 & $\begin{array}{l}\text { Glycerol } \\
\text { dehydrogenase }\end{array}$ & $g / d A$ & 220449 & 441.19 \\
\hline P69799 & $\begin{array}{l}\text { PTS system } \\
\text { mannose- } \\
\text { specific ElIAB } \\
\text { component }\end{array}$ & $\operatorname{man} X$ & 94232 & 56.71 \\
\hline B7MRV6 & $\begin{array}{l}\text { Serine-tRNA } \\
\text { ligase }\end{array}$ & serS & 16845 & 55.11 \\
\hline
\end{tabular}

alons score is $-10^{*} \log (P)$, where $P$ is the probability that the observed match is a random event. Individual ions scores $>16$ indicated identity or extensive homology $(p<0.05)$. Protein scores were derived from ions scores as a non-probabilistic basis for ranking protein hits. Cut-off was set at lons score 20. Values with 2 or more peptides per protein and a score of $>50$ were considered.

Deiminated proteins were isolated by immunoprecipitation using the pan-deimination F95 antibody and analyzed by LC-MS/MS. Peak files were submitted to Mascot.

homologs have been limited and hitherto mainly reported in P. gingivalis (Mangat et al., 2010; Bielecka et al., 2014); a Gingivalis citrullinome has also been described (Stobernack et al., 2016). An E. coli PAD/AD-like protein was detected here at approximatly $40-50 \mathrm{kDa}$, similar to that found in $P$. gingivalis (Bielecka et al., 2014; Gabarrini et al., 2018), while in comparison human PADs are 72-75 kDa (Vossenaar et al., 2003; Kosgodage et al., 2018). Multiple sequence analysis of E. coli and $S$. aureus suggested that $\mathrm{PAD} / \mathrm{AD}$ of $E$. coli and $S$. aureus are most closely related to human PAD2.

Interestingly, for inhibiting OMV/MV release from Gramnegative and Gram-positive bacteria the PAD4-specific inhibitor GSK199 was most effective while the PAD2-specific inhibitor AMF30a was least effective. Therefore, it may be postulated that the tertiary conformation of both $E$. coli and S. aureus PAD/ADs may be more similar to human PAD4, although the amino acid sequence alignment analysis indicates more similarity to PAD2, and this will require further investigation. In P. gingivalis, also a Gram-negative bacterium, PAD is believed to be evolutionarily only remotely related to human PAD2 despite the fact that both catalyze the same chemical reaction (Rodríguez et al., 2009; Bereta et al., 2019) and furthermore, point-mutation variants with differing deimination activity have also been reported in Gingivalis (Gabarrini et al., 2018; Bereta et al., 2019).

Here, F95 enrichment analysis revealed a range of deiminated proteins, both in E. coli cells and their derived OMVs, indicating lateral transfer of deiminated proteins via OMVs. Besides roles in bacterial communication, this may possibly also affect host-pathogen interactions, including immune evasion via modification of the host's proteins. For example, citrullination/deimination of complement component C5a, upon treatment with $P$. gingivalis OMVs, as opposed to in vitro treatment of C5a with PAD, has been shown to contribute to bacterial immune evasion by decreasing the chemotactic ability of neutrophils (Bielecka et al., 2014).

The citrullinome of E. coli VCS257 observed here, revealed indeed a range of metabolic, stress-response related and membrane proteins, therefore indicating diverse roles for protein deimination in bacterial cell function. Deiminated proteins identified in E. coli derived OMVs included threonine-tRNA ligase, which has not been described as being deiminated in bacterial OMVs before, but has been shown to be in OMVs from Streptococcus suis (Haas and Grenier, 2015), albeit not in deiminated form. Threonine-tRNA ligase, also known as threonine-tRNA synthetase, belongs to the family of aminoacyltRNA synthetases, which are involved in RNA splicing and transcriptional and translational regulation. They link amino acids to their cognate transfer RNAs (tRNA) in aminoacylation reactions, that establish the connection between a specific amino acid and a nucleotide triplet anticodon embedded in the tRNA (Schimmel, 2008). Also, 30S ribosomal protein was identified as being deiminated in OMVs. It is one of the primary rRNA binding proteins that bind directly to $16 \mathrm{~S}$ rRNA, where it helps nucleate assembly of the platform of the 30S subunit by binding and bridging several RNA helices of the 16S rRNA (Smith et al., 2018). In addition, 30S ribosomal protein S4 $(r p s D)$ and $\mathrm{S} 15(r p s O)$ were identified as deiminated both in the E. coli cells as well as their derived OMVs. Previously, $40 \mathrm{~S}$ ribosomal protein has been reported as a substrate of PAD4 mediated deimination/citrullination in HEK 293Tcells (Guo et al., 2011).

Furthermore, evidence of a PAD/AD-like protein exported in E. coli VCS257 derived OMVs was found. When probing the PAD4 enriched eluate with the F95 antibody, a faint positive band in the expected range for a putative bacterial $\mathrm{PAD} / \mathrm{AD}$, in the region of $50 \mathrm{kDa}$ region was observed, indicating that possibly the E. coli $\mathrm{PAD} / \mathrm{AD}$ may be deiminated itself, although the LC MS-MS analysis did not reveal a PAD/AD-like protein hit. Such a possibility of PAD/AD auto-deimination would though align with previous studies on auto-deimination of mammalian PAD4 (Slack et al., 2011) but will require further in-depth investigation. In a recent study on OMVs derived from $P$. gingivalis, it was found that Gingivalis PAD was abundant in OMVs, although no assessment was made of a deiminated PAD form or of deiminated proteins exported in OMVs (Gabarrini et al., 2018).

The effect of PAD inhibitors on OMV/MV release, as previously established for EV release in eukaryotic cells (Kholia et al., 2015; Kosgodage et al., 2017, 2018; Gavinho et al., 2019), 
TABLE 2A | PAD4 bound proteins identified in E. coli VCS257 cells.

\begin{tabular}{|c|c|c|c|c|}
\hline UniProt ID & Protein name & Abbreviation & MS2 Intensity & Score $^{a}(p<0.05)$ \\
\hline P0A895 & Lysine-tRNA ligase, heat inducible & lysU & 321997 & 300.12 \\
\hline Q8X9L0 & ATP-dependent zinc metalloprotease FtsH & $\mathrm{ftsH}$ & $1 E+06$ & 151.09 \\
\hline P0ABC5 & Modulator of FtsH protease $\mathrm{HfIC}$ & hflC & 66850 & 189.23 \\
\hline Q1R5V0 & $50 S$ ribosomal protein $\mathrm{L} 10$ & rp/J & 478659 & 218.99 \\
\hline Q8X4S5 & Arabinose 5-phosphate isomerase GutQ & gutQ & 486219 & 120.37 \\
\hline A7ZML6 & Succinylornithine transaminase & astC & 232079 & 73.58 \\
\hline B7MPT2 & Curved DNA binding protein & $\operatorname{cbpA}$ & 6123.2 & 90.68 \\
\hline P69911 & Glutamate decarboxylase beta & $\operatorname{gad} B$ & 387378 & 72.46 \\
\hline A7ZY39 & $\begin{array}{l}\text { Cyclic pyranopterin monophosphate synthase accessory } \\
\text { protein }\end{array}$ & moaC & 17232 & 67.03 \\
\hline POAGL3 & Putative reactive intermediate deaminase TdcF & $t d c F$ & 161746 & 80.57 \\
\hline Q8X710 & UPF0339 protein YegP & yegP & 6121.7 & 87.63 \\
\hline QOTFDO & $\begin{array}{l}\text { Acetyl-coenzyme A carboxylase carboxyl transferase } \\
\text { subunit- } \beta\end{array}$ & $\operatorname{acc} D$ & 156916 & 99.12 \\
\hline P0A6A5 & Acetate kinase & ackA & 79146 & 70.42 \\
\hline P0A9Q3 & Aerobic respiration control protein ArcA & $\operatorname{arc} A$ & 19035 & 60.23 \\
\hline A8A0U0 & Succinylornithine transaminase & astC & 28022 & 73.51 \\
\hline $\mathrm{POA9H4}$ & Inducible lysine decarboxylase & $\operatorname{cad} A$ & 716567 & 78.26 \\
\hline Q8FJM0 & DNA protection during starvation protein & $d p s$ & 51562 & 65.43 \\
\hline B7N1L1 & Glycine-tRNA ligase beta subunit & glyS & 23006 & 87.76 \\
\hline B7N2S2 & ATP-dependent protease ATPase subunit HsIU & HslU & 398703 & 52.01 \\
\hline Q8XBT3 & Universal stress protein $\mathrm{G}$ & uspG & 36115 & 159.67 \\
\hline POAF94 & 2-iminobutanoate/2-iminopropanoate deaminase & yjgF & 22468 & 105.18 \\
\hline
\end{tabular}

alons score is $-10^{*} \log (P)$, where $P$ is the probability that the observed match is a random event. Individual ions scores $>16$ indicated identity or extensive homology $(P<0.05)$. Protein scores were derived from ions scores as a non-probabilistic basis for ranking protein hits. Cut-off was set at lons score 20. Values with 2 or more peptides per protein and a score of $>50$ were considered.

Proteins were isolated by immunoprecipitation using the PAD4 antibody (ab96758) and analyzed by LC-MS/MS. Peak files were submitted to Mascot.

TABLE 2B | Proteins identified both in F95 and PAD4 enriched samples of E. coli VCS257 cells and derived OMVs.

\begin{tabular}{|c|c|c|c|c|c|c|}
\hline UniProt ID & Protein name & Abbreviation & \multicolumn{3}{|c|}{ MS2 intensity } & Score $^{a}(p<0.05$ \\
\hline P04949 & Flagellin & flic & 704599 & $1 \mathrm{E}+06$ & 9488.7 & 653.24 \\
\hline P0A906 & Outer membrane lipoprotein SlyB & slyB & 289574 & 555800 & 10565 & 632.79 \\
\hline Q1R636 & 30 S ribosomal protein S4 & $\operatorname{rps} D$ & 22719 & 44378 & 3554.4 & 289.35 \\
\hline
\end{tabular}

alons score is $-10^{\star} \log (P)$, where $P$ is the probability that the observed match is a random event. Individual ions scores $>16$ indicated identity or extensive homology $(P<0.05)$.

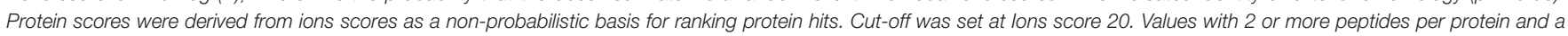
score of $>50$ were considered.

Proteins commonly identified by LC-MS/MS in both F95 and PAD4 enriched protein eluates are listed. 
reveals a phylogenetically conserved pathway from bacteria to mammals. This is also in line with findings that many commonly expressed proteins including chaperone proteins, ribonuclease, outer membrane lipoprotein, 50S ribosomal protein L22 and flagellin are believed to be targets of protein deimination (Huang et al., 2016; Claushuis et al., 2018). Importantly, the present study shows that PAD inhibitors can be used to enhance antibiotic sensitivity of selected antibiotics. PAD4 inhibitor GSK199, alongside the pan-PAD inhibitors were effective for $\mathrm{OMV} / \mathrm{MV}$ inhibition and sensitization to antibiotic treatment. Differences in mechanisms of action for the selected PAD inhibitors used in this study may need to be considered, both with regards to inhibiting vesicle release and the synergism observed with each antibiotic. Interestingly, while PAD4inhibitor GSK199 was overall the strongest OMV/MV inhibitor, albeit the pan-PAD inhibitors showed a similar trend, in some cases the pan-PAD inhibitors (Cl-am and BB-Cl-am) were more effective in sensitization to antibiotic treatment. It must also be taken into consideration that $\mathrm{BB}-\mathrm{Cl}$-amidine and Cl-amidine are hydrophilic, while AMF30a and GSK199 are hydrophobic compounds. Furthermore, GSK199 is highly lipophilic which may facilitate its uptake in the cell. The difference in hydrophobicity of the PAD inhibitors could have played a role in cell penetration, in addition to differing in specificity for inhibition of the bacterial $\mathrm{PAD} / \mathrm{AD}$, and this may therefore also have affected OMV/MV release. A recent review has demonstrated the presence of different types of vesicles released from both Gram-negative and Gram-positive bacteria, indicating also that the composition of the cell membrane plays a role in vesiculation (Toyofuku et al., 2019). The presence of a thickened peptidoglycan cell wall in Grampositive bacteria restricts the penetration of most drugs into the cells, which suggests the need of an alternative receptormediated transport system (Liu et al., 2018). However, the high lipid content of the Gram-negative cell membrane with a thin layer of peptidoglycan increases membrane fluidity thus facilitating OMV release (Roier et al., 2016). This may also facilitate the bacterial cell wall penetration of lipid soluble drugs and elicit a more effective response, as indeed observed here for GSK199.

While PAD4-mediated neutrophil extracellular trap (NET) formation is a well-known bactericidal and anti-pathogenic mechanism of the immune system ( $\mathrm{Li}$ et al., 2010; Claushuis et al., 2018; Magnadóttir et al., 2018), we have now revealed here another antibacterial mechanism, namely via $\mathrm{PAD} / \mathrm{AD}$ mediated inhibition of bacterial OMV/MV release. Bacteria may indeed utilize their PAD/AD in several ways for modulation of the host immune system and immune invasion, including via the generation of neo-epitopes, modification of host's immune proteins, such as $\mathrm{C} 5 \mathrm{a}$, and also through the release of OMV/MVs. While many studies on OMVs have been based on Gram-negative bacterial species (Pérez-Cruz et al., 2013; Bonnington and Kuehn, 2016; Roier et al., 2016), MV release from $S$. aureus has also been shown by different groups (Lee et al., 2009; Gurung et al., 2011). Interestingly, MV secretion and improper vancomycin treatment have been correlated with biofilm formation by methicillin-resistant Staphylococcus aureus (MRSA)

(He et al., 2017).

When assessing the effectivity of PAD inhibition to enhance susceptibility of Gram-positive and Gram-negative bacterial species to antibiotic treatment, E. coli VCS257 were rendered more sensitive to erythromycin, rifampicin, kanamycin and colistin, while $S$. aureus subsp. aureus Rosenbach became more sensitive to all five antibiotics tested. This increased sensitivity in both bacterial species varied though somewhat, depending on the PAD-specific inhibitors used. It must also be noted that while the zone of inhibition was statistically significant in $S$. aureus, the proportional differences observed in antibiotic sensitization were not as high as those observed in some cases for $E$. coli and therefore it will require further investigation how physiologically significant such lower, albeit statistically significant, effects are. It can also be postulated that bacteria may use PAD/AD mediated deimination as a mode of a hitherto non-described microbial strategy to evade antibiotic action, and this might also explain some differences observed with the different PAD inhibitors and will require further in-depth investigation. There was no antibacterial effect of vancomycin on E. coli VCS257, confirming its limited effectiveness on Gram-negative species and the previously established resistance of $E$. coli to vancomycin, due to its inability to significantly penetrate the outer membrane (Zhou et al., 2015). Here, colistin and vancomycin effectivity was found to be enhanced in the presence of PAD inhibitors in E. coli and S. aureus respectively, decreasing $\mathrm{MIC}$ value at varying degrees. This indicates that lower concentrations of the antibiotic may be used to treat infections with minimal damage to healthy cells. It has previously been shown that the presence of calcium decreases the bactericidal effect of colistin on Paenibacillus polymyxa, which suggests that $\mathrm{Ca}^{2+}$ modulates a protective barrier against colistin (Yu et al., 2015). As the PADs are calcium-activated enzymes, it can be postulated that downstream $\mathrm{PAD} / \mathrm{AD}$ activation and resulting $\mathrm{OMV} / \mathrm{MV}$ release via a $\mathrm{PAD} / \mathrm{AD}$ pathway may be a measure of bacterial defense against colistin treatment.

Our current study is the first to describe effects of PAD inhibitors on OMV/MV release in both a Gram-positive and Gram-negative bacterial species. PAD/AD inhibition approaches in bacteria have previously been discussed in relation to oral Gingivalis and the association to initiation of autoimmunity via the generation of neo-epitopes (Mangat et al., 2010; Montgomery et al., 2016). Pharmacological inhibition of PADs, using Cl-amidine or a PAD2/PAD4 inhibitor has also been shown to improve survival in several murine models of sepsis and LPS-induced endotoxemia (Zhao et al., 2016; Biron et al., 2017; Liang et al., 2018). Here we have shown that PAD inhibition had a significant effect on antibiotic sensitization in both species, albeit to a lower extent in S. aureus. Therefore, further identification and assessment of candidate OMV/MV inhibitors may allow for tailored application according to bacteria type and specific antibiotics.

Previous studies have discussed the use of OMVs for example as drug delivery vehicles (Ellis and Kuehn, 2010; 
A Effect of PAD inhibitors on antibiotic sensitivity of E. coli VCS257

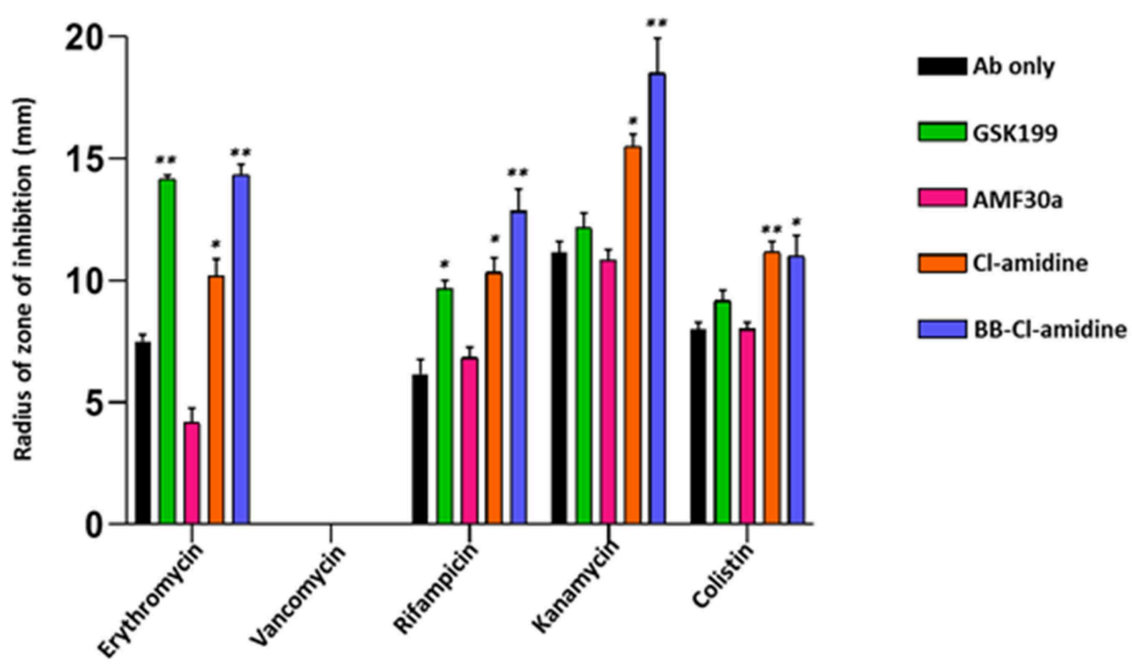

B Effect of PAD inhibitors on antibiotic sensitivity of $S$. aureus subsp. aureus Rosenbach

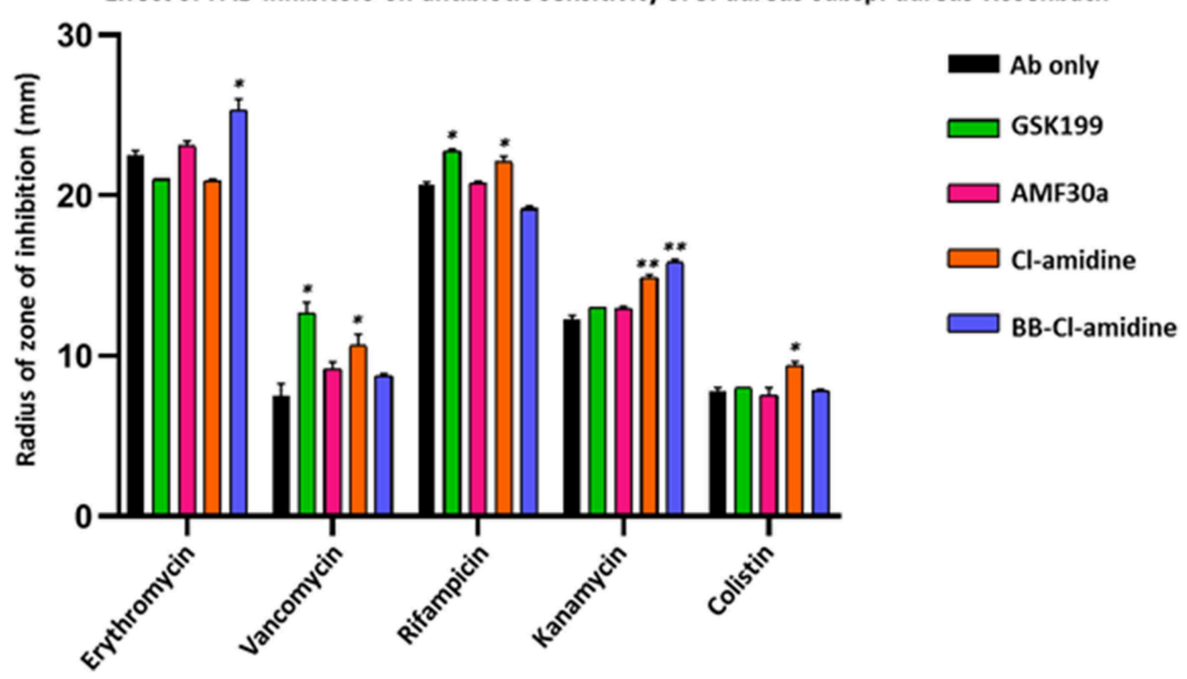

FIGURE 7 | PAD inhibitors increase antibiotic sensitivity of E. coli VCS257 and S. aureus subsp. aureus Rosenbach. (A) In E. coli, all antibiotics (Ab), except for vancomycin, had significantly increased zones of inhibition in the presence of PAD inhibitors. BB-Cl-amidine, Cl-amidine and GSK199 were effective, increasing antibiotic sensitivity of $E$. coli to erythromycin, rifampicin, kanamycin and colistin. Vancomycin was not effective against Gram-negative bacterial colonies and did not result in a zone of inhibition in the presence of any of the PAD inhibitors. (B) In S. aureus, vancomycin, rifampicin, kanamycin and colistin significantly increased their zones of inhibition in the presence of PAD inhibitors. BB-Cl-amidine enhanced bactericidal effects of erythromycin, while vancomycin was enhanced by GSK199 and $\mathrm{Cl}$-amidine. Anti-bacterial effects of rifampicin were enhanced by GSK199 and Cl-amidine. Kanamycin's zone of inhibition was increased by Cl-amidine and BB-Cl-amidine. For colistin, the zone of inhibition was increased by $\mathrm{Cl}$-amidine. Concentration of PAD-inhibitors used was as follows: PAD2 inhibitor AMF30a (5 $\mu$ M), PAD4 inhibitor, GSK199 $(10 \mu \mathrm{M})$, pan-PAD inhibitors Cl-amidine $(50 \mu \mathrm{M})$ and BB-Cl-amidine $(5 \mu \mathrm{M})$. The experiments were carried out three times and the data presented are mean \pm SEM of the results $\left({ }^{*} p \leq 0.05 ;{ }^{* *} p \leq 0.01\right)$.

Gujrati et al., 2014; Gerritzen et al., 2017; Jain and Pillai, 2017; Jan, 2017; Wang et al., 2018). OMVs have also been tested as delivery vehicles for targeted gene silencing using siRNA-packaged OMVs (Alves et al., 2016), although the exact mechanism for packaging proteins and other reagents in OMVs still remains to be fully understood. There is also an increasing interest in identification of OMV subpopulations (Pérez-Cruz et al., 2016; Bonnington and Kuehn, 2017; Turner et al., 2018; Cooke et al., 2019; Toyofuku et al., 2019; Zavan et al., 2019), as well as in assessing the importance of OMV size for cellular uptake and entry (Turner et al., 2018). Therefore, changes observed here in the NTA spectra of OMVs in response to PAD inhibitor treatment (Figures 1D-G) may be of some interest in addition to the observed reduction in total amounts of OMV/MVs released.

For the first time, the potential of using PAD inhibitors to enhance antibiotic sensitivity has been assessed, in both a 

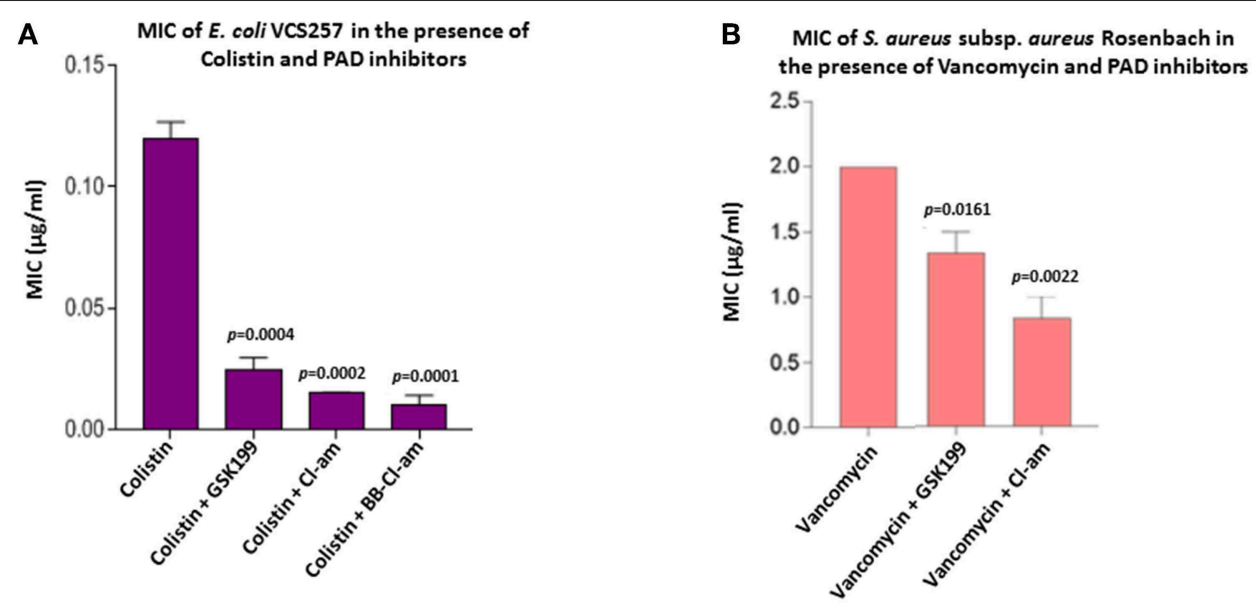

FIGURE 8 | PAD inhibitors reduce the MIC value of colistin for E. coli VCS257 and MIC value of vancomycin for S. aureus subsp. aureus Rosenbach. (A) In E. coli, $\mathrm{BB}-\mathrm{Cl}$-amidine was most effective at lowering the $\mathrm{MIC}$ value of colistin, reducing $\mathrm{MIC}$ by $91.6 \%$. Cl-amidine decreased $\mathrm{MIC}$ by $87.4 \%$, being the second most effective OMV-inhibitor lowering the MIC value of colistin. GSK199 lowered MIC by $76 \%$. The experiment was repeated thrice and the data presented are mean \pm SEM of the results; exact $p$-values are indicated. (B) In S. aureus, Cl-amidine increased the effectiveness of vancomycin by at least $62.5 \%$, while GSK199 resulted in a $25 \%$ decrease in MIC. The experiments were repeated thrice and the data presented are mean \pm SEM of the results; exact $p$-values are shown.

Gram-positive and Gram-negative bacterial species, revealing a phylogenetically conserved $\mathrm{PAD} / \mathrm{AD}$ pathway of membrane vesicle release. This may open avenues for tailored OMV/MV inhibition in combination with selected antibiotics, according to bacterial type, to regulate biofilm formation and tackle antibiotic resistance.

\section{CONCLUSION}

This study reveals a phylogenetically conserved PAD/AD pathway of OMV/MV release in bacteria that can be pharmacologically modulated to sensitize bacteria to antibiotic treatment. For the first time, a citrullinome of E. coli VCS257 and associated OMVs is described, indicating lateral transfer of deiminated proteins via OMVs. Our findings highlight new applications for $\mathrm{PAD}$ inhibitors to regulate OMV/MV release and to enhance antibiotic sensitivity in both Gram-positive and Gram-negative bacteria.

\section{DATA AVAILABILITY}

The raw data supporting the conclusions of this manuscript will be made available by the authors, without undue reservation, to any qualified researcher.

\section{AUTHOR CONTRIBUTIONS}

UK, PM, GM, IK, DB, BA, and SL performed the experiments. UK, SL, and JI analyzed the data. PM, GM, IK, AN, SL, and JI provided resources. UK, SL, and JI designed the study and wrote the manuscript. All authors critically reviewed the manuscript.

\section{FUNDING}

This work was supported in parts by the IAPP project 612224 (EVEStemInjury, REA FP7, Project No. LSC09R R3474) to JI and a University of Westminster Start-up Grant to SL. The funders had no role in study design, data collection and analysis, decision to publish, or preparation of the manuscript.

\section{ACKNOWLEDGMENTS}

The authors would like to thank Paul R. Thompson, UMASS for providing the PAD inhibitors and Vinothini Rajeeve, Queen Mary University London, for LC-MS-MS analysis. Thanks are also due to the Guy Foundation for funding the purchase of equipment utilized in this study.

\section{SUPPLEMENTARY MATERIAL}

The Supplementary Material for this article can be found online at: https://www.frontiersin.org/articles/10.3389/fcimb. 2019.00227/full\#supplementary-material

Supplementary Figure 1 | Multiple sequence alignment of $E$. coli $A D$ and human PADs. The evolutionary relationship between $E$. coli $\mathrm{AD}$ and human PAD2, 3 and 4 is shown; $\left({ }^{*}\right)$ indicates positions which have a single, fully conserved residue; (:) indicates conservation between groups of strongly similar properties - scoring $>0.5$ in the Gonnet PAM 250 matrix; (.) indicates conservation between groups of weakly similar properties, scoring $<0.5$ in the Gonnet PAM 250 matrix.

Supplementary Figure 2 | Multiple sequence alignment of $S$. aureus $A D$ and human PADs. The evolutionary relationship between $S$. aureus AD and human PAD2, 3 and 4 is shown; $\left({ }^{*}\right)$ indicates positions which have a single, fully conserved residue; (:) indicates conservation between groups of strongly similar properties - scoring $>0.5$ in the Gonnet PAM 250 matrix; (.) indicates conservation between groups of weakly similar properties, - scoring $<0.5$ in the Gonnet PAM 250 matrix.

Supplementary Figure 3 | Western blotting of immunoprecipitated deiminated proteins (F95) and PAD4 bound proteins from E. coli VCS257 and derived OMVs. 
(A) Same figure as 4C, but also showing unbound fractions (flow-through) from OMVs and E. coli after IP, using the F95 antibody. (B) Same figure as 4D, but also showing unbound fractions (flow-through) from OMVs and E. coli after IP, using the PAD4 antibody.

Supplementary Figure 4 | Agar plates showing the Kirby-Bauer disk diffusion test for E. coli VCS257 and S. aureus subsp. aureus Rosenbach. (A) Disk

\section{REFERENCES}

Alam, M. T., Petit, R. A. III, Crispell, E. K., Thornton, T. A., Conneely, K. N., Jiang, Y., et al. (2014). Dissecting vancomycin-intermediate resistance in Staphylococcus aureus using genome-wide association. Genome Biol. Evol. 6, 1174-1185. doi: 10.1093/gbe/evu092

Alves, N. J., Turner, K. B., Mendints, I. L., and Walper, S. A. (2016). Protecting enzymatic function through directed packaging into bacterial outer membrane vesicles. Sci. Rep. 6:24866. doi: 10.1038/srep 24866

Bereta, G., Goulas, T., Madej, M., Bielecka, E., Solà, M., Potempa, J., et al. (2019). Structure, function, and inhibition of a genomic/clinical variant of Porphyromonas gingivalis peptidylarginine deiminase. Protein Sci. 28, 478-486. doi: $10.1002 /$ pro.3571

Bielecka, E., Scavenius, C., Kantyka, T., Jusko, M., Mizgalska, D., Szmigielski, B., et al. (2014). Peptidyl arginine deiminase from Porphyromonas gingivalis abolishes anaphylatoxin C5a activity. J. Biol. Chem. 289, 32481-32487. doi: 10.1074/jbc.C114.617142

Biron, B. M., Chung, C. S., Chen, Y., Wilson, Z., Fallon, E. A., Reichner, J. S., et al. (2018). PAD4 deficiency leads to decreased organ dysfunction and improved survival in a dual insult model of hemorrhagic shock and sepsis. J. Immunol. 200, 1817-1828. doi: 10.4049/jimmunol.1700639

Biron, B. M., Chung, C. S., O’Brien, X. M., Chen, Y., Reichner, J. S., and Ayala, A. (2017). Cl-Amidine prevents histone 3 citrullination and neutrophil extracellular trap formation, and improves survival in a murine sepsis model. J. Innate Immun. 9, 22-32. doi: 10.1159/000448808

Bitto, N. J., and Kaparakis-Liaskos, M. (2017). The therapeutic benefit of bacterial membrane vesicles. Int. J. Mol. Sci. 18:E1287. doi: 10.3390/ijms18061287

Bonnington, K. E., and Kuehn, M. J. (2016). Outer membrane vesicle production facilitates LPS remodeling and outer membrane maintenance in salmonella during environmental transitions. mBio. 7:e01532-e01516. doi: $10.1128 / \mathrm{mBio} .01532-16$

Bonnington, K. E., and Kuehn, M. J. (2017). Breaking the bilayer: OMV formation during environmental transitions. Microb Cell 4, 64-66. doi: $10.15698 / \mathrm{mic} 2017.02 .558$

Campbell, E. A., Korzheva, N., Mustaev, A., Murakami, K., Nair, S., Goldfarb, A., et al. (2001). Structural mechanism for rifampicin inhibition of bacterial RNA polymerase. Cell. 104, 901-912. doi: 10.1016/S0092-8674(01)0 0286-0

Choi, S. J., Kim, M. H., Jeon, J., Kim, O. Y., Choi, Y., Seo, J., et al. (2015). Active immunization with extracellular vesicles derived from Staphylococcus aureus effectively protects against staphylococcal lung infections, mainly via Th1 cell-mediated immunity. PLoS ONE 10:e136021. doi: 10.1371/journal.pone.0136021

Claushuis, T. A. M., van der Donk, L. E. H., Luitse, A. L., van Veen, H. A., van der Wel, N. N., van Vught, L. A., et al. (2018). Role of peptidylarginine deiminase 4 in neutrophil extracellular trap formation and host defense during Klebsiella pneumoniae-induced pneumonia-derived sepsis. J. Immunol. 201, 1241-1252. doi: 10.4049/jimmunol.1800314

Cooke, A. C., Nello, A. V., Ernst, R. K., and Schertzer, J. W. (2019). Analysis of Pseudomonas aeruginosa biofilm membrane vesicles supports multiple mechanisms of biogenesis. PLoS ONE. 14:e0212275. doi: 10.1371/journal.pone.0212275

Costa, N. A., Gut, A. L., Azevedo, P. S., Polegato, B. F., Magalhães, E. S., Ishikawa, L. L. W., et al. (2018). Peptidylarginine deiminase 4 concentration, but not PADI4 polymorphisms, is associated with ICU mortality in septic shock patients. J. Cell Mol. Med. 22, 4732-4737. doi: 10.1111/jcmm. 13717 diffusion test for E. coli VCS257. (B) Effects of PAD inhibitor disks alone on E. coli are shown. (C) Disk diffusion test for $S$. aureus subsp. aureus Rosenbach. (D) Effects of PAD inhibitors alone on $S$. aureus are shown. Disks containing the following antibiotics are indicated: erythromycin (E), vancomycin ( $)$, Rifampicin (R), kanamycin (K), colistin (C). PAD inhibitors used were GSK199 (10 $\mu \mathrm{M}$; PAD4 inhibitor), Cl-amidine (50 $\mu \mathrm{M}$; pan-PAD inhibitor), BB-Cl-amidine ( $5 \mu \mathrm{M}$; pan-PAD inhibitor), AMF30a (5 $\mu \mathrm{M}$; PAD2 inhibitor).

Dorward, D. W., and Garon, C. F. (1990). DNA is packaged within membranederived vesicles of Gram-negative but not Gram-positive bacteria. Appl. Environ. Microbiol. 56, 1960-1962.

Ellis, T. N., and Kuehn, M. J. (2010). Virulence and immunomodulatory roles of bacterial outer membrane vesicles. Microbiol. Mol. Biol. Rev. 74, 81-94. doi: 10.1128/MMBR.00031-09

Falagas, M. E., Kasiakou, S. K., and Saravolatz, L. D. (2005). Colistin: the revival of polymyxins for the management of multidrug-resistant gram-negative bacterial infections. Clin. Inf. Dis. 40, 1333-1341. doi: 10.1086/429323

Fulsundar, S., Harms, K., Flaten, G. E., Johnsen, P. J., Chopade, B. A., and Nielsen, K. M. (2014). Gene transfer potential of outer membrane vesicles of Acinetobacter baylyi and effects of stress on vesiculation. Appl. Environ. Microbiol. 80, 3469-3483. doi: 10.1128/AEM.04248-13

Gabarrini, G., Palma Medina, L. M., Stobernack, T., Prins, R. C., du Teil Espina, M., Kuipers, J., et al. (2018). There's no place like OM: vesicular sorting and secretion of the peptidylarginine deiminase of Porphyromonas gingivalis. Virulence. 9, 456-464. doi: 10.1080/21505594.2017.1421827

Gaillard, M. E., Bottero, D., Errea, A., Ormazabal, M., Zurita, M. E., Moreno, G., et al. (2014). A cellular pertussis vaccine based on outer membrane vesicles capable of conferring both long-lasting immunity and protection against different strain genotypes. Vaccine 32, 931-937. doi: 10.1016/j.vaccine.2013.12.048

Gavinho, B, Rossi, I. V., Evans-Osses, I., and Lange, S., Ramirez, M. I. (2019). Peptidylarginine deiminase inhibition abolishes the production of large extracellular vesicles from Giardia intestinalis, affecting hostpathogen interactions by hindering adhesion to host cells. bioRxiv 586438 . doi: $10.1101 / 586438$

Gerritzen, M. J. H., Martens, D. E., Wijffels, R. H., van der Pol, L., and Stork, M. (2017). Bioengineering bacterial outer membrane vesicles as vaccine platform. Biotechnol. Adv. 5, 565-574. doi: 10.1016/j.biotechadv.2017.05.003

Goldstein, E. J. C., Citron, D. M., Tyrrell, K. L., and Leoncio, E. (2018). In vitro activity of DS-2969b and comparator antimicrobial agents against Clostridioides (Clostridium) difficile, methicillin-resistant Staphylococcus aureus, and other anaerobic bacteria. Anaerobe. 54, 39-41. doi: 10.1016/j.anaerobe.2018.04.010

Gujrati, V., Kim, S., Kim, S. H., Min, J. J., Choy, H. E., Kim, S. C., et al. (2014). Bioengineered bacterial outer membrane vesicles as cell-specific drug-delivery vehicles for cancer therapy. ACS Nano. 8, 1525-1537. doi: 10.1021/nn405724x

Gully, N., Bright, R., Marino, V., Marchant, C., Cantley, M., Haynes, D., et al. (2014). Porphyromonas gingivalis peptidylarginine deiminase, a key contributor in the pathogenesis of experimental periodontal disease and experimental arthritis. PLoS ONE 9:e100838. doi: 10.1371/journal.pone.0100838

Guo, Q., Bedford, M. T., and Fast, W. (2011). Discovery of peptidylarginine deiminase-4 substrates by protein array: antagonistic citrullination and methylation of human ribosomal protein S2. Mol Biosyst. 7, 2286-2295. doi: $10.1039 / \mathrm{c} 1 \mathrm{mb} 05089 \mathrm{c}$

Gurung, M., Moon, D. C., Choi, C. W., Lee, J. H., Bae, Y. C., Kim, J., et al. (2011). Staphylococcus aureus produces membrane-derived vesicles that induce host cell death. PLoS ONE. 6:e27958. doi: 10.1371/journal.pone.0027958

Haas, B., and Grenier, D. (2015). Isolation, characterisation and biological properties of membrane vesicles produced by the swine pathogen Streptococcus suis. PLoS ONE 10:e0130528. doi: 10.1371/journal.pone.0130528

He, X., Yuan, F., Lu, F., Yin, Y., and Cao, J. (2017). Vancomycin-induced biofilm formation by methicillin-resistant Staphylococcus aureus is associated with the secretion of membrane vesicles. Microb Pathog. 110, 225-231. doi: 10.1016/j.micpath.2017.07.004

Hoerr, V., Duggan, G. E., Zbytnuik, L., Poon, K. K., Große, C., Neugebauer, U., et al. (2016). Characterization and prediction of the mechanism of 
action of antibiotics through NMR metabolomics. BMC Microbiol. 16:82. doi: 10.1186/s12866-016-0696-5

Huang, W., Wang, S., Yao, Y., Xia, Y., Yang, X., Li, K., et al. (2016). Employing Escherichia coli-derived outer membrane vesicles as an antigen delivery platform elicits protective immunity against Acinetobacter baumannii infection. Sci. Rep. 16:37242. doi: 10.1038/srep37242

Ianaro, A., Ialenti, A., Maffia, P., Sautebin, L., Rombolà, L., Carnuccio, R., et al. (2000). Anti-inflammatory activity of macrolide antibiotics. J. Pharmacol. Exp. Therapeut. 292, 156-163. Available online at: http://jpet.aspetjournals.org/ content/292/1/156.long

Iqbal, J., Siddiqui, R., Kazmi, S. U., and Khan, N. A. (2013). A simple assay to screen antimicrobial compounds potentiating the activity of current antibiotics. Biomed. Res. Int. 2013:927323. doi: 10.1155/2013/927323

Jain, S., and Pillai, J. (2017). Bacterial membrane vesicles as novel nanosystems for drug delivery. Int. J. Nanomed. 12, 6329-6341. doi: 10.2147/IJN.S137368

Jan, A. T. (2017). Outer membrane vesicles (OMVs) of gram-negative bacteria: a perspective update. Front. Microbiol. 8:1053. doi: 10.3389/fmicb.2017.01053

Jelić, D., and Antolović, R. (2016). From erythromycin to azithromycin and new potential ribosome-binding antimicrobials. Antibiotics 5:29. doi: 10.3390/antibiotics5030029

Kholia, S., Jorfi, S., Thompson, P. R., Causey, C. P., Nicholas, A. P., Inal, J. M., et al. (2015).A novel role for peptidylarginine deiminases in microvesicle release reveals therapeutic potential of PAD inhibition in sensitizing prostate cancer cells to chemotherapy. J. Extracell. Vesicl. 4:26192. doi: 10.3402/jev.v4. 26192

Klimentova, J., and Stulik, J. (2015). Methods of isolation and purification of outer membrane vesicles from gram negative bacteria. Microbiol. Res. 170, 1-9. doi: 10.1016/j.micres.2014.09.006

Knight, J. S., Luo, W., O’Dell, A. A., Yalavarthi, S., Zhao, W., Subramanian, V., et al. (2014). Peptidylarginine deiminase inhibition reduces vascular damage and modulates innate immune responses in murine models of atherosclerosis. Circ. Res. 114, 947-956. doi: 10.1161/CIRCRESAHA.114.303312

Kosgodage, U. S., Onganer, P. U., Maclathcy, A., Kraev, N., Chatterton, N., Nicholas, A. P., et al. (2018). Peptidylarginine deiminases post-translationally deiminate prohibitin and modulate extracellular vesicle release and micrornas in glioblastoma multiforme. Int. J. Mol. Sci. 28:E103. doi: 10.3390/ijms200 10103

Kosgodage, U. S., Trindade, R. P., Thompson, P. R., Inal, J. M., and Lange, S. (2017). Chloramidine/bisindolylmaleimide-I-mediated inhibition of exosome and microvesicle release and enhanced efficacy of cancer chemotherapy. Int. J. Mol. Sci. 18:1007. doi: 10.3390/ijms18051007

Kshetry, A. O., Pant, N. D., Bhandari, R., Khatri, S., Shrestha, K. L., Upadhaya, S. K., et al. (2016). Minimum inhibitory concentration of vancomycin to methicillin resistant Staphylococcus aureus isolated from different clinical samples at a tertiary care hospital in Nepal. Antimicrob. Resist. Infect. Control. 5:27. doi: 10.1186/s13756-016-0126-3

Kulkarni, H. M., Nagaraj, R., and Jagannadham, M. V. (2015). Protective role of E. coli outer membrane vesicles against antibiotics. Microbiol. Res. 181:1-7. doi: 10.1016/j.micres.2015.07.008

Lange, S., Gallagher, M., Kholia, S., Kosgodage, U. S., Hristova, M., Hardy, J., et al. (2017). Peptidylarginine deiminases-roles in cancer and neurodegeneration and possible avenues for therapeutic intervention via modulation of exosome and microvesicle (EMV) release? Int. J. Mol. Sci. 18:E1196. doi: $10.3390 / \mathrm{ijms} 18061196$

Lee, E. Y., Choi, D. Y., Kim, D. K., Kim, J. W., Park, J. O., Kim, S., et al. (2009). Gram-positive bacteria produce membrane vesicles: proteomics-based characterization of Staphylococcus aureus-derived membrane vesicles. Proteomics 9, 5425-5436. doi: 10.1002/pmic.2009 00338

Lepe, J. A., Domínguez-Herrera, J., Pachón, J., and Aznar, J. (2014). Determining accurate vancomycin MIC values for methicillin-resistant Staphylococcus aureus by the microdilution method. J. Antimicrob. Chemother. 69, 136-138. doi: $10.1093 / \mathrm{jac} / \mathrm{dkt} 308$

Lewis, H. D., Liddle, J., Coote, J. E., Atkinson, S. J., Barker, M. D., Bax, B. D., et al. (2015). Inhibition of PAD4 activity is sufficient to disrupt mouse and human NET formation. Nat. Chem. Biol. 11, 189-191. doi: 10.1038/nchembio.1735

Li, P., Li, M., Lindberg, M. R., Kennett, M. J., Xiong, N., and Wang, Y. (2010). PAD4 is essential for antibacterial innate immunity mediated by neutrophil extracellular traps. J. Exp. Med. 207, 1853-1862. doi: 10.1084/jem.20 100239

Li, Z., Clarke, A. J., and Beveridge, T. J. (1998). Gram- negative bacteria produce membrane vesicles which are capable of killing other bacteria. J. Bacteriol. 180, 5478-5483.

Liang, Y., Pan, B., Alam, H. B., Deng, Q., Wang, Y., Chen, E., et al. (2018). Inhibition of peptidylarginine deiminase alleviates LPS-induced pulmonary dysfunction and improves survival in a mouse model of lethal endotoxemia. Eur. J. Pharmacol. 833, 432-440. doi: 10.1016/j.ejphar.2018.07.005

Liu, W., Tan, M., Zhang, C., Xu, Z., Li, L., and Zhou, R. (2018). Functional characterization of murB-potABCD operon for polyamine uptake and peptidoglycan synthesis in Streptococcus suis. Microbiol. Res. 207, 177-187. doi: 10.1016/j.micres.2017.11.008

Livermore, D. M., Warner, M., Mushtaq, S., Doumith, M., Zhang, J., and Woodford, N. (2011). What remains against carbapenem-resistant Enterobacteriaceae? Evaluation of chloramphenicol, ciprofloxacin, colistin, fosfomycin, minocycline, nitrofurantoin, temocillin and tigecycline. Int. J. Antimicrob. Agents 37, 415-419. doi: 10.1016/j.ijantimicag.2011.01.012

Luo, Y., Knuckley, B., Lee, Y. H., Stallcup, M. R., and Thompson, P. R. J. (2006). A fluoroacetamidine-based inactivator of protein arginine deiminase 4: design, synthesis, and in vitro and in vivo evaluation. Am. Chem. Soc. 128, 1092-1093. doi: $10.1021 /$ ja0576233

Macdonald, I. A., and Kuehn, M. J. (2013). Stress-induced outer membrane vesicle production by Pseudomonas aeruginosa. J. Bacteriol. 195, 2971-2981. doi: 10.1128/JB.02267-12

Maclayton, D. O., Suda, K. J., Coval, K. A., York, C. B., and Garey, K. W. (2006). Case-control study of the relationship between MRSA bacteremia with a vancomycin MIC of $2 \mathrm{microg} / \mathrm{mL}$ and risk factors, costs, and outcomes in inpatients undergoing hemodialysis. Clin. Ther. 28, 1208-1216. doi: 10.1016/j.clinthera.2006.08.003

Magnadóttir, B., Hayes, P., Hristova, M., Bragason, B. T., Nicholas, A. P., Dodds, A. W., et al. (2018). Post-translational protein deimination in cod (Gadus morhua L.) ontogeny - novel roles in tissue remodelling and mucosal immune defences? Dev. Comp. Immunol. 87, 157-170. doi: 10.1016/j.dci.2018.06.006

Mangat, P., Wegner, N., Venables, P. J., and Potempa, J. (2010). Bacterial and human peptidylarginine deiminases:targets for inhibiting the autoimmune response in rheumatoid arthritis? Arthrit. Res. Ther. 12:209. doi: $10.1186 / a r 3000$

Manning, A. J., and Kuehn, M. J. (2011). Contribution of bacterial outer membrane vesicles to innate bacterial defense. BMC Microbiol. 11:258. doi: 10.1186/1471-2180-11-258

Maresz, K. J., Hellvard, A., Sroka, A., Adamowicz, K., Bielecka, E., Koziel, J., et al. (2013). Porphyromonas gingivalis facilitates the development and progression of destructive arthritis through its unique bacterial peptidylarginine deiminase (PAD). PLoS Pathog. 9:e1003627. doi: 10.1371/journal.ppat.1003627

McBroom, A. J., and Kuehn, M. J. (2007). Release of outer membrane vesicles by Gram-negative bacteria is a novel envelope stress response. Mol. Microbiol. 63, 545-558. doi: 10.1111/j.1365-2958.2006.05522.x

McCaig, W. D., Koller, A., and Thanassi, D. G. (2013). Production of outer membrane vesicles and outer membrane tubes by Francisella novicida. J. Bacteriol. 195, 1120-1132. doi: 10.1128/JB.02007-12

Montgomery, A. B., Kopec, J., Shrestha, L., Thezenas, M. L., BurgessBrown, N. A., Fischer, R., et al. (2016). Crystal structure of Porphyromonas gingivalis peptidylarginine deiminase: implications for autoimmunity in rheumatoid arthritis. Ann. Rheum. Dis. 75, 1255-1261. doi: 10.1136/annrheumdis-2015-207656

Moskowitz, S. M., Garber, E., Chen, Y., Clock, S. A., Tabibi, S., Miller, A. K., et al. (2010). Colistin susceptibility testing: evaluation of reliability for cystic fibrosis isolates of Pseudomonas aeruginosa and Stenotrophomonas maltophilia. J. Antimicrob. Chemother. 65, 1416-1423. doi: 10.1093/jac/dkq131

Muth, A., Subramanian, V., Beaumont, E., Nagar, M., Kerry, P., McEwan, P., et al. (2017). Development of a selective inhibitor of protein arginine deiminase 2. J. Med. Chem. 60, 3198-3211. doi: 10.1021/acs.jmedchem.7b00274

Ng, K., Mabasa, V. H., Chow, I., and Ensom, M. H. (2014). Systematic review of efficacy, pharmacokinetics, and administration of intraventricular vancomycin in adults. Neurocrit. Care 20, 158-171. doi: 10.1007/s12028-012-9784-z

Nicholas, A. P., and Whitaker, J. N. (2002). Preparation of a monoclonal antibody to citrullinated epitopes: its characterization and some 
applications to immunohistochemistry in human brain. Glia 37, 328-336. doi: 10.1002/glia.10039

Pérez-Cruz, C., Cañas, M. A., Giménez, R., Badia, J., Mercade, E., Baldomà, L., et al. (2016). Membrane vesicles released by a hypervesiculating Escherichia coli Nissle 1917 tolR mutant are highly heterogeneous and show reduced capacity for epithelial cell interaction and entry. PLOS ONE 11:e0169186. doi: 10.1371/journal.pone.0169186

Pérez-Cruz, C., Carrión, O., Delgado, L., Martinez, G., López-Iglesias, C., and Mercade, E. (2013). New type of outer membrane vesicle produced by the Gram-negative bacterium Shewanella vesiculosa $\mathrm{M}^{\mathrm{T}}$ : implications for DNA content. Appl. Environ. Microbiol. 79, 1874-1881. doi: 10.1128/AEM.03657-12

Raeven, R. H., Brummelman, J., Pennings, J. L., van der Maas, L., Tilstra, W., Helm, K., et al. (2016). Bordetella pertussis outer membrane vesicle vaccine confers equal efficacy in mice with milder inflammatory responses compared to a whole-cell vaccine. Sci. Rep. 6:38240. doi: 10.1038/srep38240

Rodríguez, S. B., Stitt, B. L., and Ash, D. E. (2009). Expression of peptidylarginine deiminase from Porphyromonas gingivalis in Escherichia coli: enzyme purification and characterization. Arch. Biochem. Biophys. 488, 14-22. doi: 10.1016/j.abb.2009.06.010

Roier, S., Zingl, F. G., Cakar, F., Durakovic, S., Kohl, P., Eichmann, T. O., et al. (2016). A novel mechanism for the biogenesis of outer membrane vesicles in Gram-negative bacteria. Nat. Commun. 7:10515. doi: 10.1038/ncomms10515

Rojas, L. J., Salim, M., Cober, E., Richter, S. S., Perez, F., Salata, R. A., et al. (2017). Antibacterial resistance leadership group. colistin resistance in carbapenemresistant Klebsiella pneumoniae: laboratory detection and impact on mortality. Clin. Infect Dis. 64, 711-718. doi: 10.1093/cid/ciw805

Salian, S., Matt, T., Akbergenov, R., Harish, S., Meyer, M., Duscha, S., et al. (2012). Structure-activity relationships among the kanamycin aminoglycosides: role of ring I hydroxyl and amino groups. Antimicrob. Agents Chemother. 56, 6104-6108. doi: 10.1128/AAC.01326-12

Schimmel, P. (2008). Development of tRNA synthetases and connection to genetic code and disease. Protein Sci. 17, 1643-1652. doi: 10.1110/ps.037242.108

Schooling, S. R., and Beveridge, T. J. (2006). Membrane vesicles: an overlooked component of the matrices of biofilms. J. Bacteriol. 188, 5945-5957. doi: 10.1128/JB.00257-06

Slack, J. L., Jones, L. E., Bhatia, M. M., and Thompson, P. R. (2011). Autodeimination of protein arginine deiminase 4 alters proteinprotein interactions but not activity. Biochemistry 50, 3997-4010. doi: 10.1021/bi200309e

Smith, B. A., Gupta, N., Denny, K., and Culver, G. M. (2018). Characterization of 16S rRNA processing with Pre-30S subunit assembly intermediates from $E$. coli. J. Mol. Biol. 430, 1745-1759. doi: 10.1016/j.jmb.2018.04.009

Stobernack, T., Glasner, C., Junker, S., Gabarrini, G., de Smit, M., de Jong, A., et al. (2016). Extracellular proteome and citrullinome of the oral pathogen Porphyromonas gingivalis. J. Proteome Res. 15, 4532-4543. doi: 10.1021/acs.jproteome.6b00634

Toyofuku, M., Nomura, N., and Eberl, L. (2019). Types and origins of bacterial membrane vesicles. Nat. Rev. Microbiol. 17, 13-24. doi: 10.1038/s41579-018-0112-2

Turner, L., Bitto, N. J., Steer, D. L., Lo, C., D’Costa, K., Ramm, G., et al. (2018). Helicobacter pylori outer membrane vesicle size determines their mechanisms of host cell entry and protein content. Front. Immunol. 9:1466. doi: 10.3389/fimmu.2018.01466

van Ingen, J., Aarnoutse, R. E., Donald, P. R., Diacon, A. H., Dawson, R., Plemper van Balen, G., et al. (2011). Why do we use $600 \mathrm{mg}$ of rifampicin in tuberculosis treatment? Clin. Infect. Dis. 52:e194-e199. doi: 10.1093/cid/cir184
Vossenaar, E. R., Zendman, A. J., van Venrooij, W. J., and Pruijn, G. J. (2003). PAD, a growing family of citrullinating enzymes: genes, features and involvement in disease. Bioessays 25, 1106-1118. doi: 10.1002/bies. 10357

Wang, S., Huang, W., Li, K., Yao, Y., Yang, X., Bai, H., et al. (2017). Engineered outer membrane vesicle is potent to elicit HPV16E7-specific cellular immunity in a mouse model of TC-1 graft tumor. Int. J. Nanomed. 12, 6813-6825. doi: 10.2147/IJN.S143264

Wang, S., and Wang, Y. (2013). Peptidylarginine deiminases in citrullination, gene regulation, health and pathogenesis. Biochim. Biophys. Acta 1829, 1126-1135. doi: 10.1016/j.bbagrm.2013.07.003

Wang, X., Thompson, C. D., Weidenmaier, C., and Lee, J. C. (2018). Release of Staphylococcus aureus extracellular vesicles and their application as a vaccine platform. Nat. Commun. 9:1379. doi: 10.1038/s41467-01803847-z

Watanakunakorn, C. (1984). Mode of action and in-vitro activity of vancomycin. J. Antimicrob. Chemother. 14 (Suppl. D), 7-18. doi: 10.1093/jac/14. suppl_D.7

Witalison, E. E., Thompson, P. R., and Hofseth, L. J. (2015). Protein arginine deiminases and associated citrullination: physiological functions and diseases associated with dysregulation. Curr. Drug Targets 16, 700-710. doi: 10.2174/1389450116666150202160954

Yahav, D., Farbman, L., Leibovici, L., and Paul, M. (2012). Colistin: new lessons on an old antibiotic. Clin. Microbiol. Infect. 18, 18-29. doi: 10.1111/j.1469-0691.2011.03734.x

Yu, Z., Cai, Y., Qin, W., Lin, J., and Qiu, J. (2015). Polymyxin E induces rapid Paenibacillus polymyxa death by damaging cell membrane while $\mathrm{Ca} 2+$ can protect cells from damage. PLoS ONE 10:e0135198. doi: 10.1371/journal.pone.0135198

Yu, Z., Zhang, L., Qin, W., Yin, J., and Qiu, J. (2019). Exogenous catalase stimulates the Polymyxin E induced rapid killing of Paenibacillus polymyxa. Int. J. Pept. Res. Ther. 25, 161-168. doi: 10.1007/s10989-017-9657-6

Zavan, L., Bitto, N. J., Johnston, E. L., Greening, D. W., and Kaparakis-Liaskos, M. (2019). Helicobacter pylori growth stage determines the size, protein composition, and preferential cargo packaging of outer membrane vesicles. Proteomics. 19:e1800209. doi: 10.1002/pmic.201970004

Zhao, T., Pan, B., Alam, H. B., Liu, B., Bronson, R. T., Deng, Q., et al. (2016). Protective effect of $\mathrm{Cl}$-amidine against CLP-induced lethal septic shock in mice. Sci. Rep. 6:36696. doi: 10.1038/srep36696

Zhou, A., Kang, T. M., Yuan, J., Beppler, C., Nguyen, C., Mao, Z., et al. (2015). Synergistic interactions of vancomycin with different antibiotics against Escherichia coli: trimethoprim and nitrofurantoin display strong synergies with vancomycin against wild-type E. coli. Antimicrob, Agents Chemother. 59, 276-281. doi: 10.1128/AAC.03502-14

Conflict of Interest Statement: The authors declare that the research was conducted in the absence of any commercial or financial relationships that could be construed as a potential conflict of interest.

Copyright (C) 2019 Kosgodage, Matewele, Mastroianni, Kraev, Brotherton, Awamaria, Nicholas, Lange and Inal. This is an open-access article distributed under the terms of the Creative Commons Attribution License (CC BY). The use, distribution or reproduction in other forums is permitted, provided the original author(s) and the copyright owner(s) are credited and that the original publication in this journal is cited, in accordance with accepted academic practice. No use, distribution or reproduction is permitted which does not comply with these terms. 